\title{
Study on high efficient heat recovery cycle for solid-state cooling
}

\author{
Suxin Qian, Jiazhen Ling, Jan Muehlbauer, Yunho Hwang*, Reinhard Radermacher \\ Center for Environmental Energy Engineering, Department of Mechanical Engineering, University of \\ Maryland, 4164 Glenn L. Martin Hall Bldg., College Park, MD 20742, USA \\ *Corresponding Author
}

Tel: (+1) 301-405-5247, Fax: (+1) 301-405-2025, Email: yhhwang@umd.edu

\begin{abstract}
Traditional vapor compression cycles (VCCs) use mainly halogenated refrigerants such as hydrochloroflurocarbons and hydrofluorocarbons that are considered as greenhouse gases. Therefore, their regulations are imposed on a global scale. As an alternative cooling technology other than VCCs, solid-state cooling technologies, such as magnetic cooling, thermoelastic cooling and electrocaloric cooling, demonstrate its advantage of not using greenhouse gases as working fluids. However, one of the most challenging issues of these solid-state cooling technologies is the relative high parasitic internal latent heat loss, which could significantly deteriorate the system performance. In order to improve the system performance of solid-state cooling, the authors propose a novel and high-efficient heat recovery (HR) cycle for solid-state materials with high thermal conductivity. The novel heat recovery process was first compared as an analog of spatial scale counter-flow heat transfer process. A simplified ideal model was developed to quantitatively investigate the heat recovery process performance limit and the physics behind the analogy of the spatial scale counter-flow heat transfer process. Experiment was conducted and $60 \%$ HR efficiency was achieved. In addition, a detailed dynamic model validated by the experiment results was developed and used to further investigate the limiting factors together with the theoretical analysis.
\end{abstract}

Key words: Solid-state cooling, thermal wave, heat recovery, regeneration, thermoelastic cooling 


\section{Nomenclature}

\section{Symbols}

\begin{tabular}{|c|c|}
\hline $\mathrm{Bi}$ & Biot number \\
\hline$c_{p}$ & specific heat $\left[\mathrm{J} \cdot \mathrm{kg}^{-1} \cdot \mathrm{K}^{-1}\right]$ \\
\hline$D$ & diameter $[\mathrm{m}]$ \\
\hline Fo & Fourier number \\
\hline GWP & global warming potential \\
\hline HCFCs & Hydrochloroflurocarbons \\
\hline HFCs & Hydrofluorocarbons \\
\hline HR & heat recovery \\
\hline HTF & heat transfer fluid \\
\hline$h$ & heat transfer coefficient $\left[\mathrm{W} \cdot \mathrm{m}^{-2} \cdot \mathrm{K}^{-1}\right]$ \\
\hline$I D$ & internal diameter $[\mathrm{m}]$ \\
\hline$k$ & thermal conductivity $\left[\mathrm{W} \cdot \mathrm{m}^{-1} \cdot \mathrm{K}^{-1}\right]$ \\
\hline$l$ & length $[\mathrm{m}]$ \\
\hline$l^{*}$ & non-dimensional length \\
\hline$L M T D$ & log-mean temperature difference $[\mathrm{K}]$ \\
\hline$O D$ & outer diameter $[\mathrm{m}]$ \\
\hline ODE & ordinary differential equations \\
\hline$Q$ & heat transferred $[\mathrm{J}]$ \\
\hline$\dot{Q}$ & capacity [W] \\
\hline$R$ & resistance \\
\hline$S$ & entropy $\left[\mathrm{J} \cdot \mathrm{kg}^{-1} \cdot \mathrm{K}^{-1}\right]$ \\
\hline sec & second \\
\hline $\bar{r}$ & non-dimensional ratios \\
\hline
\end{tabular}


temperature $\left[{ }^{\circ} \mathrm{C}\right]$

temperature change rate $\left[\mathrm{K} \cdot \mathrm{s}^{-1}\right]$

time, or duration [sec]

non-dimensional cycle duration

fluid mean velocity $\left[\mathrm{m} \cdot \mathrm{s}^{-1}\right]$

internal volume of pipe $\left[\mathrm{m}^{3}\right]$

volumetric flow rate $\left[\mathrm{m}^{3} \cdot \mathrm{s}^{-1}\right]$

vapor compression cycle

thermal diffusivity $\left[\mathrm{m}^{2} \cdot \mathrm{s}^{-1}\right]$

equivalent thickness [m]

effectiveness

non-dimensional latent heat

heat recovery efficiency

thermal mass factor

density $\left[\mathrm{kg} \cdot \mathrm{m}^{-3}\right]$

\section{Subscripts}

$\begin{array}{ll}\text { A-B } & \text { From Solid A to Solid B } \\ \text { ad } & \text { adiabatic } \\ \text { cyc } & \text { cycle } \\ \text { hp } & \text { fluid } \\ \text { init } & \text { heat pump } \\ \text { s } & \text { initial } \\ \text { tot } & \text { solid, solid heat exchanger } \\ & \text { total }\end{array}$




\section{Introduction}

The desire to reduce the environmental impact from the high GWP refrigerants, such as hydrochloroflurocarbons (HCFCs) and hydrofluorocarbons (HFCs) used in air-conditioning and refrigeration systems has been intensifying since the past decades. Other than finding substitute refrigerants, utilizing alternative cooling technologies based on solid-state materials with zero GWP could be considered as one of the solutions to this issue. The major difference of those two technologies is that most solid-state cooling technologies (magnetocaloric, thermoelastic, and electrocaloric) operate in a cyclic manner, while the state-of-the-art vapor compression cycle (VCC) operates in continuous manner other than control purpose. In addition, solid-state cooling has other advantages over the VCC cooling, such as less noise, no high pressure components, and low maintenance cost (Yu et al., 2012, Sharp et al., 2006, Yazaki et al., 2002). However, the solid-state cooling technologies have disadvantages hindering their market development. Besides the high cost of the prototypes, these solid-state cooling have less useful cooling power as compared with the traditional VCC does due to the so-called parasitic internal latent heat losses. These losses are attributed to the sensible heat required to change the temperature of the material itself between two temperature levels that, in the context of heat pumps, are the heat sink and heat source during its cyclic operation. The parasitic internal loss is exemplified in the VCC operation by the vapor quality increase of refrigerant as it flows through the expansion device. Part of the cooling generated from this process causes decrease of the refrigerant temperature from the condensing temperature to the evaporating temperature. For solid-state cooling, it has the similar amount of parasitic loss as that in the VCC, however, the solid-state materials have much smaller latent heat than those of the VCC refrigerants. As a consequence, the remaining useful cooling power of solid-state materials is much lower than those of the VCC refrigerants. In order to quantify the above-mentioned difference, the nondimensional latent heat, defined by Eq. (1) in a similar manner to Alefeld and Radermacher's work (1994), is applied for both VCC refrigerants and some typical solid-state materials, and the results are listed in Table 1. In Eq. (1), the numerator is the latent heat generated through different mechanisms, and the 
denominator represents the material's parasitic internal latent heat. We define a ratio called adiabatic temperature span, $\Delta T_{a d}$, so that Eq. (1) can be simplified as the ratio between the adiabatic temperature span and the heat pump's temperature lift. The simplified term can also be recognized as a normalized adiabatic temperature span.

$$
\gamma=\frac{T \Delta S}{c_{p} \Delta T_{h p}}=\frac{\Delta T_{a d}}{\Delta T_{h p}}
$$

where $\Delta T_{a d} \equiv \frac{T \Delta S}{c_{p}}$ is defined as the measure of the latent heat in most of the solid-state cooling

literatures. $\Delta T_{h p} \equiv T_{\text {sink }}-T_{\text {source }}$ is the measure of the temperature lift of the system as used in most of the thermodynamics textbooks.

Based on the above definition, the index $\gamma$ is a measure of the "available latent heat ratio". A higher index value indicates more portion of latent heat is available for "useful" cooling. In the case of $\gamma$ is greater than 1, the latent heat generated by the cooling mechanism is more than the parasitic internal latent heat loss inside the cooling cycle. If the ratio is less than 1, the cycle fails to generate any "useful" cooling. However, as explained in the latter part, it may still work if it is aided by certain heat recovery mechanisms. From Table 1, it is obvious that the VCC refrigerants have much higher $\gamma$ than the others due to their large amount of latent heat, while $\gamma$ of most solid-state materials are either below or around 1. Nevertheless, the solid-state cooling could still work since the parasitically consumed latent heat in the denominator of Eq. (1) is not necessarily as large as the latent heat in the numerator. Instead, it could be compensated by the heat recovery process (also known as regeneration or recuperation process in magnetic refrigeration and electrocaloric cooling field), which is represented by the internal heat transfer between two streams flowing in reverse directions between heat sink and heat source. Another approach is reducing the denominator by smaller temperature lift and multi-stage heat pump, i.e. cascade cycle, which is beyond the scope of this study. Therefore, the current study is focused on HR process in order 
for the solid-state materials to achieve the large temperature lift required for air-conditioning or heat pump applications.

Figure 1 explains the role of heat recovery in a typical cyclic solid-state cooling cycle (a reverse Brayton cycle for thermoelastic cooling as an example proposed by Qian et al., 2014). To accomplish the cycle, two solid heat exchangers (solid A and solid B) are needed. The beginnings of first half cycle and second half cycle $(0 \rightarrow 1$ and $3 \rightarrow 4)$ are the adiabatic processes, which occur when the governing mechanism release or absorb latent heat such as compression/tension for thermoelastic cooling and magnetization/demagnetization for magnetic cooling. The second parts $(1 \rightarrow 2$ and $4 \rightarrow 5)$ are the heat transfer processes between the solids with two streams of fluids from the heat sink $\left(T_{\mathrm{h}}\right)$ and heat source $\left(T_{\mathrm{c}}\right)$. The heat recovery processes are right after heat transfer processes $(2 \rightarrow 3$ and $5 \rightarrow 6)$ between solid A and solid B. It should be noted that the temperatures of two solids switch between $T_{\mathrm{c}}$ and $T_{\mathrm{h}}$ as the cycle continues at the beginning of the heat recovery process. From energy flow point of view, during process $0 \rightarrow 1$ and $3 \rightarrow 4$, the driving energy transforms into the source of the heating and cooling effect, which is later transferred to heat source and sink via heat transfer process. If we isolate the HR process, HR itself does not generate any cooling or heating effect. Instead, it is driven by a previously formed temperature difference.

Various heat recovery methodologies have been proposed and applied in different applications. The most straight forward heat recovery technology has been used in adsorption air-conditioning and refrigeration cycles for decades (Qian et al. 2013). Some advanced heat recovery cycle were proposed in order to enhance the heat recovery efficiency and achieve energy conservation (Shelton et al., 1989, Shelton et al., 1990, Harkonen and Aittomaki, 1991, Critoph, 1994, Critoph, 1998, and Pons and Poyelle, 1997, Sun et al., 1997). The essence of these methodologies is achieving a propagating steep temperature gradient inside the adsorption bed, named as "thermal-wave". However, these high efficient heat recovery cycles were proposed for heat recuperation between adsorbent beds, of which the thermal conductivity of the solid bed is typically low enough to ignore the conduction along the internal heat 
transfer fluid (HTF) flow direction. In fact, the thermal conductivity of silica gel, a typical adsorbent, is between $0.1-0.2 \mathrm{~W} / \mathrm{m} \cdot \mathrm{K}$ (Gurgel and Kluppel, 1996). Such thermal conductivity is at least two magnitude less than the thermal conductivity of SMA, which is $18 \mathrm{~W} / \mathrm{m} \cdot \mathrm{K}$ for Ni-Ti alloy and over 100 $\mathrm{W} / \mathrm{m} \cdot \mathrm{K}$ for copper based SMAs such as Cu-Zn-Al (Otsuka and Wayman, 1998). Since the conductivities of the solid-state materials discussed in this study are generally much higher than those of the solid desiccant materials in the adsorption beds, the heat conduction along the solid-state material itself could neutralize the temperature gradient and significantly deteriorate the overall heat recovery performance. Therefore, the traditional "thermal-wave" proposed for adsorption cooling is not suitable for solid-state material's heat recovery. A brief comparison between the near square shaped thermal-wave heat recovery for adsorption cooling, and the triangle shaped thermal-wave heat recovery for solid-state cooling is illustrated in Figure 2 (a) and (b), respectively.

There were several other regeneration methodologies used in magnetic cooling and electrocaloric cooling fields, both of which use a single solid-state material to achieve heat pumping processes by generating temperature gradients inside the single material. Differently from the adsorption heat recovery, the heat recuperation hereby consists of infinite numbers of local heat recovery processes between the regenerator and the solid-state material. During the heat rejecting process, only one side of the solid material is rejecting heat to the heat sink while the rest rejects energy to the regenerator to achieve the heat recovery. The most widely used magnetic refrigerator working at near room temperatures incorporated with the so-called active magnetic regenerator (AMR) to increase its performance and temperature span significantly (Zimm et al., 2006, Richard et al., 2004). The AMR, in fact, is more than a single HR process between two solids as because it utilizes a combination of serially connected internal HR and cascade heat pumping processes by enhancing HTF in reciprocating manner or circulating periodically. Despite the variation in how the cycles are cascaded locally (Cross et al., 1988, Hall et al. 1996), the heat regeneration process was achieved by cycling fluid internally back and forth between the heat sink and heat source. Recently, Gu et al. (2013) demonstrated an oscillatory refrigerator prototype 
based on electrocaloric principle while using solid-to-solid contact heat transfer design to regenerate cooling and heating between the high and low temperature solid-state materials by the solid regenerator. The heat recovery was achieved by periodically slipping the solid material to maintain a small heat transfer temperature difference between the solid-state material and the regenerator, which is similar to AMR design and the only difference is whether fluid or solid is used as the regenerator. These two approaches offer rational for a guideline in constructing equivalent heat recovery options for other solidstate cooling mechanisms, such as thermoelastic cooling. In these approaches, the heat recovery (HR) should be accomplished between the solid-state material and a temperature varying media to minimize the irreversibility caused by heat transfer temperature difference. As summarized, high efficient HR process is essential to solid-state cooling and very challenging. Therefore, the objective of this study is to provide some insights on how to develop high efficient HR process for solid-state cooling by utilizing materials with relatively high thermal conductivity. Experiments and a detailed transient model were developed to validate the proposed HR method. The proposed HR process could be used for the above mentioned metal based solid-state cooling technologies.

\section{Novel thermal-wave heat recovery for solid-state materials}

This section is to introduce what the novel thermal-wave heat recovery process is and how it works in the following order:

- Provide an overview of the novel thermal-wave design concept for high conductivity solid application

- Propose the principle of "time scale counter-flow heat recovery process"

- Explain how to use a fluid with temperature gradient to achieve the "time scale counter-flow heat recovery process"

- Explain how to design the heat recovery process to generate and maintain the fluid with such a temperature gradient 

materials that have the same amount of thermal mass. For example, solid A (a.k.a. solid heat exchanger A) starts from the low temperature and solid B begins with the high temperature. Again, the driving potential of the isolated HR process is the preset temperature difference before the HR process. The objective is to "swap" the temperature level between these two solids. Since the solid won't flow like a fluid, usually a fluid is needed to achieve the "temperature swap" process between solid A and B. During the HR process, the fluid needs to absorb sensible energy from solid B and provide cooling to solid B at the same time, and then deliver the absorbed heat to solid A. To conserve energy, the amount of energy taken from solid B has to be the same as that absorbed by solid A. One can expect a direct contact of the two solids will result in the reach of equilibrium after a certain period of time, however, with a good design, one can achieve even higher efficiency, that solid A ends up with temperature even higher than solid B. In the ideal case, solid B could be completely cooled down to the initial temperature of solid A, as shown in section 3, while in practical, it is always higher than that due to limited heat transfer ability.

Here we introduce the novel thermal-wave heat recovery concept by comparing between the traditional thermal-wave used for low-conductivity solids heat recovery application (adsorption cycle), and the novel thermal-wave developed for solid materials with high conductivity (solid-state cooling), as shown in Figure 2. Both Figure 2 (a) and (b) use color to indicate the temperature level of solid, and use the solid line position to indicate the temperature of fluid. The three figures of Figure 2 (a) depicts two thermal waves moving from left to right to heat solid A and to cool solid B, respectively. The adsorption thermal-wave used the solid beds as regenerator, by supplying constant inlet temperature HTF into both beds. The low thermal conductivity nature allows a much faster heat transfer between the solid desiccant bed and the HTF than the conduction inside the desiccant to allow the formation of the steep temperature gradient inside the solid beds. On the other hand, our proposed HR process uses HTF as the regenerator, by varying fluid inlet temperature into both beds. In this case, the conduction inside the solid beds are 
essentially even faster than the heat transfer between solid bed and HTF, and therefore the triangle temperature gradient in Figure 2 (b) is for fluid, not for solid.

\subsection{Novel thermal-wave heat recovery concept}

The idea of the novel thermal-wave heat recovery cycle stems from the concept of a simple counter-flow heat exchanger, where the inlet temperature of fluid A is lower than that of fluid $\mathrm{B}$. If the two streams share the same flow heat capacity rate and the heat transfer area is infinity, the outlet temperature of fluid A will be the same as the inlet temperature of fluid B. In reality, the outlet temperature of fluid A is always lower than that of fluid B. The idea of "counter-flow" design is to minimize the temperature difference between two flow streams everywhere throughout the heat exchanger. Such idea can be analogized on a "time scale", i.e. the temperature difference between solid and contacting fluid should be minimized "everywhere at any time". To follow this idea, the fluid entering both solid heat exchangers should have a minimum temperature difference from the solid heat exchangers at any moment throughout the HR process. The analogy between the physical parameters describing the "spatial scale counter-flow" heat transfer process and "time scale counter-flow heat recovery process is quantitatively listed in Table 2. This analogy could also be expressed by Figure 3 (a) and (b). Figure 3 (a) demonstrates two fluids' temperatures on a spatial scale in a counter-flow heat transfer process with a large heat transfer area, where the outlet temperature of stream A is approaching the inlet temperature of stream B. Top plot of Figure 3 (b) demonstrates the two solids' temperature variations on a time scale during the HR process, together with the temperatures of their corresponding inlet fluid. Again, the color here indicates the temperature level for both solids and fluid. The green solid and dashed lines are corresponding to the heat transfer fluid circulating between two solids. As indicated by the same figure, the inlet fluid temperature for A and B needs to vary with time accordingly to achieve the "counter-flow" design idea. Therefore, the next question is how to develop these two green lines in Figure 3 (b), i.e. fluid passing two solid heat exchangers while changing temperature with time. 


\subsection{How to vary the solid inlet fluid temperature with time}

As it is demonstrated in the top plot of Figure 3 (b), during the "counter-flow" HR process, the fluid at the inlets of solids A and B should vary its temperature with time, so that solid A is heated gradually through one "counter-flow in time" process, and solid B is cooled down steadily through another one. Following two approaches were used to illustrate the physics behind this process.

Mathematical approach: the energy conservation equation for fluid inside the connecting pipe between A and B is shown in Eq. (2), where fluid conduction, viscous dissipation, and heat transfer with pipeline wall could be ignored:

$$
\frac{\mathrm{D} T_{f}}{\mathrm{D} t}=\frac{\partial T_{f}}{\partial t}+\vec{u} \cdot \nabla T_{f}=\nabla \cdot\left(\alpha_{f} \nabla T_{f}\right)+\Phi+\frac{4 h\left(T_{\text {wall }}(x, t)-T_{f}\right)}{\rho c_{p} D}=0
$$

Here $\mathrm{D} T_{\mathrm{f}} / \mathrm{D} t$ means the material time derivative of the spatial scalar field $T_{\mathrm{f}}$. The solid A inlet fluid temperature can be obtained by solving Eq. (3):

$$
\left.\frac{\partial T_{f}(x, t)}{\partial t}\right|_{A, \mathrm{x}=0}=-u \nabla T_{f}(u t, t=0)
$$

If the left side term is a constant, it indicates that $T_{\mathrm{f}}$ is changing linearly with time. As a result, it means that an "initial condition" with uniform temperature gradient inside the pipe is required. It should be noted here that a linear temperature profile is not strictly needed for HR, but it's good for a better performance, as is discussed in section 3 regarding ideal HR cycle analysis.

Physical approach: As indicated by the snapshots in the bottom plot of Figure 3 (b), the fluid between solids A and B has a linear temperature gradient profile varying between $T_{\mathrm{A} \text {,init }}$ and $T_{\mathrm{B} \text {, init. Now }}$ how the fluid temperatures of two solid inlets (green arrow positions in Figure 3 (b)) vary according to the incoming fluid temperature gradient is explained. Taking solid A inlet as an example, from the plot, it can be observed that hotter fluid arrives later than colder fluid. As a result, the solid A inlet fluid temperature varies from $T_{\mathrm{A} \text {,init }}$ to $T_{\mathrm{B} \text {,init }}$ when the fluid travels the exact distance of the connecting pipe between solids A and $\mathrm{B}$, which is exactly our goal in section 2.1. 
Both approach leads to one conclusion that a fluid between solids A and B with "preset" temperature distribution between $T_{\mathrm{A} \text {,init }}$ and $T_{\mathrm{B}, \text { init }}$ is required to achieve the "counter-flow" HR idea. It should be noted that based on our assumption in Eq. (2), the temperature gradient is required for the fluid inside the connecting pipe, rather than for the pipe wall. The contribution of connecting pipe wall to the HR efficiency is discussed later. The next question is: how to generate such a fluid with the required temperature gradient and how to maintain it?

\subsection{How to produce the fluid with a stored temperature gradient}

The way to generate such a fluid with stored temperature gradient is in fact quite simple: it's a naturally generated, and self-enhanced process, once the cycle duration is controlled precisely to be $t_{1}$ (defined in Table 3 of section 3 ). In other words, if the cycle duration is $t_{1}$, and the system reaches the socalled "cyclic steady state", there will be a smooth fluid temperature profile close to linear distribution inside connecting pipe. Here cyclic steady state is referred to temperatures varying periodically over cycles at any locations in the system.

First we'll discuss what it means by "naturally generated". At the beginning, all solids and fluids are in equilibrium before one starts the cooling cycle and the heat recovery cycle. In other words, the temperature distribution at the beginning is uniform at an intermediate temperature. Figure 4 shows the snapshots of temperature distribution inside two connecting pipes at different time during the cyclic heat recovery process, which was simulated based on the ideal case study in session 3 using Simulink (Anon., 2012 ). Recall the role of heat recovery in the whole cycle in Figure 1, and keep in mind that the solids A and B temperatures change either to $T_{\mathrm{h}}$ or $T_{\mathrm{c}}$ in every half cycle. At the very beginning, when solid $\mathrm{A}$ is at $T_{\mathrm{c}}$ and solid $\mathrm{B}$ is at $T_{\mathrm{h}}$, the fluid temperature drops a little when passing through solid $\mathrm{A}$, and generates a "temperature peak" or a spike in the first time step. The neighboring fluid flows in and contacts with solid A in the next time step, but could only absorb less heat. This part of fluid will pass solid B during the next half heat recovery cycle when solid B is switched to $T_{\mathrm{c}}$, and the fluid will be further cooled down with the development of the "low temperature peak". The accumulation of the newly developed peaks eventually 

part of fluid and the "cold peak" in this part of fluid are fully developed and do not change over cycles, we develop our desired fluid with temperature distribution between $T_{\mathrm{c}}$ and $T_{\mathrm{h}}$ in the connecting pipe. This "naturally-generated" temperature gradient is an evolving result from any initial temperature profile to the cyclic steady state temperature profile. The results are based on the ideal heat recovery cycle developed in section 3. The above described "naturally generated" process is assuming that the heat transfer rate between solid and fluid is not infinite for an easier understanding. The limiting case when the heat transfer coefficient reaches infinity will be discussed in section 3 .

The feature of self-enhancing is more intuitive to understand. Take the connecting pipe from A to B in Figure 2 (b) for example. If initially we have a fluid with a temperature gradient with higher temperature on the right side, as indicated by (i), the solid B is cooled down with minimum temperature difference between B and inlet fluid to solid B through the heat recovery process using the temperature gradient between solids A and B. Let us focus on the particle at lowest temperature inside this connecting pipe flowing towards solid B, as indicated by (ii). At the end of the heat recovery process, the particle moves to the outlet of the connecting pipe (iii). Meanwhile, we notice that a reversed temperature gradient has been established with higher temperature on the left as it compared with (i). Therefore, during the next heat recovery cycle when solid B is going to be heated up instead of cooled down, the reversed temperature gradient will achieve the counter-flow heat recovery process once again. In this way, the fluid temperature gradient is developed as heat recovery cycle continues.

In a summary, we developed the concept of "counter-flow in time scale", focusing on minimizing the temperature difference between the fluid and solid during the heat transfer process, by circulating fluid with varying temperature between the solids A and B. This fluid temperature variation inside solid is achieved by a self-generated and self-sustaining smooth temperature gradient in the connecting pipe between solids A and B, when a set of conditions are satisfied. The coming sessions of this study 
discusses and tests the importance of these conditions from three points of view: ideal case, real experiment, and realistic modeling, before listing the design guidelines in session 5.3.

\section{Ideal heat recovery cycle analysis}

The objective of this part is to find the limit of the proposed HR method by ideal case analysis, and identifying the simplest limitation factors, similar to discussing how to approach $100 \%$ counter-flow heat exchanger effectiveness. More realistic factors, such as considering the temperature distribution inside solid beds, or fluid conduction, are discussed in a more sophisticated simulation in session 5 .

\subsection{What is ideal heat recovery cycle}

Ideal heat recovery cycle analysis is to rank different parameters based on their impacts on the efficiency of heat recovery process. One can then neglect most of the minor irreversibility and simplify the heat recovery model. It should be noted that the ideal heat recovery cycle does not guarantee a $100 \%$ efficiency. Instead, it's a simple model that describe the most important features of the "time scale counter-flow heat recovery process" while ignoring those minor details.

The following assumptions are necessary to model the ideal heat recovery cycle:

- Solid conductivity is infinite.

- Solid acts as a point thermal mass with uniform temperature

- The wall of the connecting pipe has zero thermal mass

- The connecting pipe has uniform pipe diameter along the length

- Negligible fluid conductivity

- No viscous dissipation

- Uniform fluid temperature at any cross-section (one-dimensional simplification)

- No internal heat source/sink for fluid/solid (there is no energy conversion process during the isolated HR process)

High thermal conductivity and short solid bed length are two facts and motivations for a point thermal mass (zero-dimension) assumption. The discrepancy between the ideal HR performance and the 
Here $\delta_{\mathrm{x}, \mathrm{L}}$ is the Kronecker's delta function, indicating that the heat transfer from solid to fluid only takes place at either $x=L($ solid A) or $x=2 L$ (solid B). For any $x$ other than these two options, the right hand side of the equation is zero.

\subsection{Sufficient conditions for ideal heat recovery efficiency}

An analytical analysis yields the following solution in Eq. (6), with an initial condition of linear temperature profile in Eq. (7). The three non-dimensional ratios and three non-dimensional time constants in Eq. (6) are defined in Table 3. To investigate the sufficient conditions satisfying ideal heat recovery efficiency, we needs to look into the efficiency in "cyclic steady state". In other words, one more condition needs to be considered to guarantee ideal heat recovery efficiency other than the efficiency itself is $100 \%$, i.e. the temperature profile in the connecting pipe at the end of any heat recovery cycle should be the same as the initial temperature profile in the other heat recovery pipe, as shown in Eq. (8). Solution for solid A during first heat recovery cycle with given initial condition is: 


$$
\begin{aligned}
& T_{A}(t)=T_{h}-\frac{\left(T_{h}-T_{c}\right) t}{t_{1}}+\left(T_{h}-T_{c}\right) \bar{r}_{1} \bar{r}_{3}\left(1-\exp \left(-\frac{t}{t_{2}}\right)\right) \\
& T_{f}(L, t)=T_{h}-\frac{\left(T_{h}-T_{c}\right) t}{t_{1}}+\left(T_{h}-T_{c}\right) \frac{\bar{r}_{1}\left(\left(\bar{r}_{3}+1\right) 1\left(1-\exp \left(-\frac{t}{t_{2}}\right)\right)+\bar{r}_{2}\left(\bar{r}_{3}-\bar{r}_{2}\right)\left(1-\exp \left(-\frac{t}{t_{3}}\right)\right)\right)}{\left(\bar{r}_{3}+1-\bar{r}_{2}\right)\left(\bar{r}_{3}+1\right)} \quad 0 \leq t \leq t_{1} \\
& \text { Initial condition: } \begin{array}{l}
T_{A}(0)=T_{h} \\
T_{B}(0)=T_{c}, T_{f}(x, 0)=T_{h}-\left(T_{h}-T_{c}\right) \frac{x-L}{L} \quad L \leq x \leq 2 L
\end{array}
\end{aligned}
$$

Equivalent conditions for an ideal heat recovery cycle efficiency under "cyclic steady state" are:

$$
\eta_{c}=\frac{T_{A}(0)-T_{A}\left(t_{1}\right)}{T_{A}(0)-T_{B}(0)}=1-\bar{r}_{1} \bar{r}_{3}\left(1-\exp \left(-\frac{t_{1}}{t_{2}}\right)\right)=100 \%
$$

$\Delta T_{f}\left(x, t_{1}\right)=T_{f}\left(x, t_{1}\right)-T_{f}(L+x, 0)=\left(T_{h}-T_{c}\right) \frac{\bar{r}_{1}\left(\left(\bar{r}_{3}+1\right) 1\left(1-\exp \left(-\frac{t_{1}-\frac{x}{u}}{t_{2}}\right)\right)+\bar{r}_{2}\left(\bar{r}_{3}-\bar{r}_{2}\right)\left(1-\exp \left(-\frac{t_{1}-\frac{x}{u}}{t_{3}}\right)\right)\right.}{\left(\bar{r}_{3}+1-\bar{r}_{2}\right)\left(\bar{r}_{3}+1\right)}=0$

Both solid temperature and outlet fluid temperature in Eq. (6) consist of two parts: the first part is the first two terms, which are result of the upstream flow with an initial condition of linear temperature distribution. The second part is the third term that represents the deviation from the upstream flow, caused by the unbalance between the solid thermal storage rate and fluid heat transfer rate. To satisfy the two equations in Eq. (8), the second part in both equation of Eq. (6) needs to be zero, which means that the both the solid and the fluid inside it need to precisely follow the incoming fluid temperature profile. That is to say the temperature patterns of both solid and fluid have to match with each other, or can be understand as a balance has to be for the traditional heat exchangers in time scale:

- Solid absorbing/rejecting heat speed needs to be matched with incoming fluid temperature variation speed.

- Fluid inside solid heat exchanger absorbing/rejecting heat speed needs to be matched with incoming fluid temperature variation speed. 
To quantitatively describe the flow balancing principle mentioned above, we can find two sets of solutions to Eq. (8).

Sufficient condition \#1: $\overline{r_{1}}=0$, finite other non-dimensional ratios and finite time constants. This means that either the solid thermal mass needs to be infinitesimal, or the fluid thermal mass inside the connecting pipe needs to be infinite. Under this case, there is no requirement for heat transfer coefficient.

Sufficient condition \#2: $t_{2}=0, t_{3}=0, \overline{r_{3}}=0$, finite $t_{1}$, and finite other non-dimensional ratios. If both the solid and the fluid inside the connecting pipe have finite thermal mass, $100 \%$ efficiency is still achievable by letting $h A$ to be infinite.

Both conditions are not achievable in reality, as a counter-flow heat exchanger with $100 \%$ effectiveness does not exist either. On the contrary, our goal is always to minimize the heat transfer irreversibility as much as we can, for both transient heat recovery here, and steady state heat transfer as well. Nevertheless, the two conditions here provide some insight on how to improve the heat recovery efficiency, as we'll see their contributions summarized in Table 3.

To approach the $\overline{r_{1}}=0$ limit, since the solid bed thermal mass is not zero, the fluid thermal mass in between needs to be infinity. It results in infinitely large HR pipe in between. In reality, this first order effect holds, but will eventually be cancelled by finite HR pipe wall thermal mass resistance. The second limit, $\overline{r_{3}}=0$, suggests that the heat transfer coefficient $h A$ needs to be infinitely large, which still holds in reality. In addition, deviations from those prerequisite assumptions also lead to degradations in reality. Any finite dimensions or finite thermal conductivity of the solid bed results in finite time heat transfer within the solid, contributing to a lag from the fluid temperature and caused irreversibility. Connecting pipe geometries, including the wall thermal mass, are also factors contributing to the transient resistance, since the wall absorbs/rejects heat cyclically to the fluid flowing in them. Fluid conductivity and friction dissipation tend to disturb the preferred linear temperature distribution within the HR pipes, which are fortunately small enough for common HTFs such as water. Also, the 1D simplification for fluid temperature means that the fluid turbulence is infinitely large to allow fully mixing in any cross-section 
areas. In reality, a radial temperature profile always leads to additional temperature difference between the fluid and the solid. A larger flow rate helps to mix the fluid, but also increases $\overline{r_{3}}$ significantly. When assuming 1D flow, less flow rate is always better. The last assumption is no internal heat source/sink, which is invalid when pumps are used with mechanical efficiency less than $100 \%$. Heat is rejected into fluid locally inside pump, as well as friction dissipation along the entire fluid loop. All of the above mentioned deviations from ideal analysis and their impacts will be discussed and summarized Table 8 .

\section{Validation approach}

\subsection{Experimental set up}

As shown in Figure 6, a small scale HR test facility was developed in the lab. Two stainless steel (SS316) tubes were adopted as the simulated solid-state material beds, since the thermophysical properties of stainless steels are close to those of $\mathrm{Ni}-\mathrm{Ti}$ alloy, which is one of the most promising thermoelastic material. The two tested stainless steel were insulated externally. Water was used as the heat transfer fluid for both heat recovery and temperature control. The HR was achieved by two HR pipes storing the required smooth temperature gradient and the flow was driven by a variable speed pump between two stainless steel test sections. Solenoid valves were installed on both sides to control the fluid flow. During the test, two objective temperatures were needed before each HR cycle, i.e. one high level temperature and one low level temperature. An inline heater as the heat source, as well as an ice-cooled coil as the heat sink, were adopted to control the targeted initial temperatures of the solid-state material. Note that the heater as well as the heat sink were simply used to simulate the thermoelastic effect and the associated heat transfer process described in Figure 1, before the HR process discussed in this study. The HR process is driven by the preset temperature difference from the heater and the heat sink. Circulating pumps and solenoid valves were installed on both cooling loop and heating loop for control purposes. The heater's capacity was $1.5 \mathrm{~kW}$, and was controlled by "on-off" switch from the PID controller. The icecooled coils had a designed capacity around $0.5 \mathrm{~kW}$, and the capacity was tuned with the mixing valve. Some detailed information in terms of the test facility are listed in Table 4. 
The test procedure is described below. During the first half cycle, \#1 test section was heated and \#2 test section was cooled to the desired temperature levels before the HR cycle began. During the HR cycle, the fluid was circulated between two test sections following the proposed principle to cool test section \#1 and heat up test section \#2 in an opposite way. The second half cycle began after the first HR cycle and was operated in the opposite way compared with the first half cycle. The test section \#1 and \#2 were cooled and heated, respectively. The second HR cycle operated as the same manner compared with the first one, except the goal was to heat up the \#1 test section and cool down the \#2 test section. A detailed valve sequence is presented in Table 5.

During the test, the temperature profiles of both the test sections surface and the fluid inside them were measured by T-type thermocouples grid and recorded in every second. There were ten thermocouples in each test section, including five inserted into the stainless steel tube to measure the fluid temperature and the other five attached onto the test section surface. A Coriolis flow meter was installed on the bypass line in order to measure the HR flow rate, with calibrated accuracy of $0.1 \mathrm{~g} / \mathrm{s}$. During the normal heat recovery testing, the flow meter was not used and therefore MFM valve was always closed. Only under the flow rate testing circumstances, the top HR valve was closed and MFM valve was switched to open. It should be noted that the flow meter was not intended to measure the instantaneous flow rate, but to generate a map to estimate the relative flow velocity under different HR pump operating speed conditions. The thermocouples were calibrated over the required temperature span within $0.3^{\circ} \mathrm{C}$. The Coriolis flow meter had an accuracy of $0.1 \mathrm{~g} / \mathrm{s}$.

\subsection{One-dimensional transient model (real case)}

To help understanding the experimental results and investigate possible performance improvements, a one-dimensional transient model was developed and implemented into Simulink (Anon., 2012). This model was similar to the ideal case model to some extent, but some of the idealized assumptions were removed and was fitted to real case better. Table 6 lists the main differences for a better understanding. The following assumptions were used for this model: 
(1) Symmetric conduction in radial direction through solid test section could be simplified using lump method, since the Biot number using pipe thickness was less than 0.01, when assuming a free convection boundary condition with water. As a result, only the conduction through axial direction (or flow direction) inside solid was considered.

(2) Adiabatic boundary condition between metal and surrounding ambient air.

(3) Uniform fluid temperature at any cross-section. Based on this assumption only the convection in flow direction was considered.

(4) No internal heat source/sink (there is no energy conversion process during the isolated HR process).

(5) No heat loss from the solid test section to surrounding ambient at fluid inlet and outlet boundaries.

(6) Assuming the transient response from the solid structures of the connecting HR pipe, valves and pumps to the fluid temperature variation was fast enough, so that the wall temperature of HR pipes were the same as local fluid temperature. The thermal mass of the pipe walls were added to the thermal mass of the corresponding fluid to consider their transient effect.

Based on the above assumptions, the transient one-dimensional model could be described by the temperature of fluid and the solid as following:

$$
\begin{aligned}
& \frac{\partial T_{s}}{\partial t}=\alpha_{s} \frac{\partial^{2} T_{s}}{\partial x^{2}}-\frac{h}{\delta \cdot\left(\rho c_{p}\right)_{s}}\left(T_{s}-T_{f}\right) \\
& \frac{\partial T_{f}}{\partial t}=\alpha_{f} \frac{\partial^{2} T_{f}}{\partial x^{2}}-\frac{4 h}{I D \cdot\left(\rho c_{p}\right)_{f}}\left(T_{f}-T_{s}\right)-u_{f} \frac{\partial T_{f}}{\partial x}
\end{aligned}
$$

Here in both equations, the first right hand term was the conduction in the flow direction. The second term was the heat transfer between the fluid and solid. The third term was the most dominant one, the convection term, which was not appeared in Eq. (9) since there was no bulk movement in the solid. The internal flow heat transfer coefficient could be evaluated based on Dittus-Boelter correlation or laminar 
flow analytical solution. Note that for Eq. (9), there is no source term, since no energy conversion takes place during the isolated HR process. The energy equation used in the system study is beyond the scope of the HR process (Qian et al., 2014). The geometry parameter $\delta$ in Eq. (9) could be calculated based on Eq. (11):

$\delta=\frac{\Delta V_{s}}{\Delta A}=\frac{\left(O D^{2}-I D^{2}\right)}{4 I D}$

With boundary conditions for both solid and fluid:

$$
\begin{aligned}
& \left.\frac{\partial T_{s}}{\partial t}\right|_{x=0, x=L}=0 \\
& \left.T_{f}\right|_{x=0}=T_{f, i n}
\end{aligned}
$$

And initial condition

$$
T_{s}(x)=T_{0}, T_{f}(x)=T_{0}, 0 \leq x \leq L
$$

The connecting HR pipes, pump, and valves were also one-dimensional models, considering the thermal mass as the sum of the fluid and neighboring solid wall in Eq. (12):

$$
\frac{\partial T_{f}}{\partial t}=\frac{k_{f}}{\kappa\left(\rho c_{p}\right)_{f}} \frac{\partial^{2} T_{f}}{\partial x^{2}}-\frac{h}{\kappa\left(\rho c_{p}\right)_{f} \delta}\left(T_{f}-T_{a m b}\right)-\frac{u_{f}}{\kappa} \frac{\partial T_{f}}{\partial x}
$$

Eq. (12) is a combination of Eq. (9) and (10) to reduce the computation cost, where the fluid temperature and wall temperature were assumed to be the same, denoted by $T_{\mathrm{f}}$. The thermal mass of pipes walls, pump body, and valves body were considered by the $\kappa$ term in Eq. (12), defined as the ratio between the total thermal mass per unit length and the thermal mass of the fluid per unit length in Eq. (13). The values of this factor for the pipes applied in the test facility were listed in Table 4 . For ideal cycle, $\kappa=$ 1. 


$$
\kappa=\frac{\left(m c_{p}\right)_{f}+\left(m c_{p}\right)_{s}}{\left(m c_{p}\right)_{f}}=\frac{\left(\rho c_{p}\right)_{f} \Delta V_{f}+\left(\rho c_{p}\right)_{s} \Delta V_{s}}{\left(\rho c_{p}\right)_{f} \Delta V_{f}}=\frac{\left(\rho c_{p}\right)_{f} I D^{2}+\left(\rho c_{p}\right)_{s}\left(O D^{2}-I D^{2}\right)}{\left(\rho c_{p}\right)_{f} I D^{2}}
$$

Finite difference routine was used and implemented to Simulink. Fixed-step ODE solver was chosen to solve the set of equations above.

\section{Results and discussion}

The validation of the one-dimensional transient model by experimental data is given first, and some insight of the thermal-wave propagation using the modeling result are discussed afterwards. Parameters contributing to the HR performance are discussed based on the modeling results. A design guideline for future work is provided at last.

\subsection{Experimental results and model validation}

Figure 7 shows the average temperature profiles of two test sections over 5.5 cycles under one test condition. The heater's setpoint was $33^{\circ} \mathrm{C}$ and the ice-cooled $\mathrm{HX}$ was maintained at $18^{\circ} \mathrm{C}$ to provide a $15^{\circ} \mathrm{C}$ temperature span for the heat recovery process. Each half-cycle began with a 40 seconds temperature control process, when the temperature curves were approaching the two temperature limits. Again, the temperature control process was the artificial phase change and the heat transfer process aiming to provide the simulated initial temperature for the HR process, referring to Figure 1 . Then the HR process took place at the end of each half-cycle. The HR half-cycle ended before those small spikes in Figure 7 , and the corresponding heat recovery efficiencies were calculated after the system reached a cyclic steady state condition. Those spikes were due to flow mixing at the beginning of temperature control process, between the $\mathrm{T}$-junction of the heating/cooling loop and the $\mathrm{T}$-junction of the heat recovery loop, as shown in Figure 7. The mixing effect should be minimized in real systems to reduce the irreversibility generated by the flow mixing. 
Three sets of tests were conducted at different heat recovery flow rate conditions to validate the model by varying the flow rate and the heat recovery duration. Only three optimum points were shown in Figure 8. Although there was slightly discrepancy between cooling and heating efficiencies, they were within the measurement uncertainty tolerance range. The maximum experimentally achieved HR efficiency was $60 \%$, which could be regarded as a successful sign of the proposed method, since it already beat the $50 \%$ parallel-flow heat transfer limit. Nevertheless, there are still a lot to improve between $60 \%$ and $100 \%$, and experimentally validated one dimensional numerical model is a good way to understand such gap and find the further improvement solutions.

The three data points in Figure 8 were compared with the model prediction under the same operating conditions. Table 7 listed the comparison results, and less than 5\% relative deviation was achieved in all cases. To visualize this small difference, Figure 9 (a) shows a comparison between the experimental data and simulation data in the 15 seconds case (5\% deviation case). Figure 9 (a) already filtered the temperature control process, and therefore only HR processes were displayed during each cycle for the experimental data. Also, the experimental data in Figure 9 (a) are sampled from the measured results shown in Figure 7. Two major differences could be observed here: the "flat" period at the beginning of each cycle was less-estimated by the model, and the model was not able to predict some random nonsmooth sections in the experimental curves. The first discrepancy could be explained by the assumptions used in the model that the local HR pipe wall is in equilibrium with the local fluid. In reality, however, the equilibrium is never established during the transient heat recovery process in finite time, and the HR pipe wall delays the thermal-wave propagation, therefore increases the duration of the "flat" period. The second discrepancy could be caused by random disturbances during the test, such as trapped bubbles in the HR pipe. Nevertheless, the model predicts a similar pattern as the experiment, and therefore could be used in the next section to investigate the validity and physics of the novel thermal-wave heat recovery design. Figure 9 (b) plotted the fluid temperatures entering each bed against the solids. Recall the graphical temperature patterns on the time scale in Figure 7(b), Part 1 of this study, the fluid and solid 
temperature curves should be as parallel to each other as possible to approach the counter-flow HR concept. Back to Figure 9 (b), the temperature difference between the fluid and the solid average temperature was almost uniform in most of the time, which is corresponding to the previously developed concept. A detailed analysis for both the fluid and solid temperature variation within the HR process is carried out in the next session.

\subsection{Insight of thermal-wave propagation}

Earlier, the ideal cycle heat recovery was analyzed to have a linear temperature distribution. Here, a "real" temperature profile snapshots analysis is presented based on the experimentally validated "real" model in Figure 10, in order to compare between "ideal" case and "real" case. If we focus on the solid A inlet fluid temperature variation trend with the solid A temperature, the two temperatures increase with almost a uniform temperature difference at any time step before $70 \%$ of the process, where the heat is from the fluid with stored temperature profile in the HR pipe 2. The rest $30 \%$ of the process is the additional heating due to delay caused by the finite solid bed length. When we track the temperature distribution variation, the temperature profiles in Figure 10 inside the connecting pipes are close to but not a linear distributions, and the deviation from ideal case is because of real case irreversibility. Overall, the almost linear temperature profile within the two HR pipes and even part of the two solids are functioning as a similar manner to the suggested concept in Part 1.

There are several observations from Figure 10:

(1) The two tracing particles travel the same distance during the HR process, which is a little bit more than the length of one solid bed plus the length of one HR pipe. In ideal case, the cycle duration $t_{1}$ is the traveling time for a single heat recovery pipe, since the length of solid bed is negligible.

(2) The thermal-wave peak amplitude reduces while along traveling through the HR pipe. In other words, the HR pipe wall acts as a damping force to the transient thermal-wave. In ideal case, the 

wall is zero.

(3) There is slight temperature difference along the solid bed during the HR process. Based on the "counter-flow in time scale" principle, the temperature gradient inside solid bed itself neutralizes part of the additional heating/cooling, therefore limits a potentially higher efficiency. As a result, a shorter solid bed is possibly to achieve a higher heat recovery efficiency. In ideal case, the solid length is zero, and there is no such temperature glide.

There are a lot of variables contributing to the heat recovery efficiency, such as solid bed geometries, HR pipe geometries and thermal properties, flow rate, and cycle duration. However, these variables affect the HR efficiency through a few non-dimensional parameters rather than contributing independently. Here the most significant non-dimensional numbers are introduced. Eq. (14) is the non-dimensional heat recovery duration, which is defined by the ratio between the heat recovery duration and the time required by any particle in the flow to travel the distance that is equal to the length of one solid bed and one HR pipe. If $t^{*}=2$, then during one HR cycle, a particle inside the flow travels one circuit to the same location where it starts. Eq. (15) is the non-dimensional length, characterizing the percentage a particle in the flow travels within one of the solid bed through the HR process. Case $l^{*}=1$ is corresponding to zero HR pipe length limit, and $l^{*}=0$ is corresponding to zero solid bed length limit. For ideal heat recovery cycle in Part 1 of this paper, $t^{*}=1$ and $l^{*}=0$. There are two real factors contributing to deviation from 0 for $l^{*}$. The first is the finite axial conduction caused by non-zero bed length, since any non-zero bed length with finite thermal conductivity results in non-uniform bed temperature distribution along flow direction. The second is the additional time for the fluid to flow within the solid bed.

$$
t^{*}=\frac{t_{\mathrm{HR}}}{t_{\text {travel }}}=\frac{t_{\mathrm{HR}}}{\frac{L}{u}+\frac{L_{\mathrm{HR}, \mathrm{A}-\mathrm{B}}}{u_{\mathrm{HR}, \mathrm{A}-\mathrm{B}}}}=\frac{t_{H R} \dot{V}}{V+V_{\mathrm{HR}, \mathrm{A}-\mathrm{B}}}
$$




$$
l^{*}=\frac{t_{\text {solid }}}{t_{\text {travel }}}=\frac{L / u}{L / u+L_{\mathrm{HR}, \mathrm{A}-\mathrm{B}} / u_{\mathrm{HR}, \mathrm{A}-\mathrm{B}}}=\frac{V}{V+V_{\mathrm{HR}, \mathrm{A}-\mathrm{B}}}
$$

Based on the definition of $t^{*}$ and the observation (1) from Figure 10, $t^{*}$ should be slightly higher than 1 to achieve the "counter-flow in time scale" HR design. Figure 11 plots simulation results with various solid bed geometry, HR pipe geometry as well as different cycle duration and flow velocity. It's obvious that the optimum efficiency occurs when $t^{*}$ is around 1.25, which also validates our observation (1). Based on the operating principle, if the thermal mass of the HR pipe is zero, then the optimum $t^{*}$ should be 1, which is the same as the ideal case. Such deviation comes from both the delay caused by the connecting pipe wall thermal mass, and the finite diffusion speed inside solid bed as well.

Figure 11 also indicates a minimum efficiency when $t^{*}$ is around 0.9 . The physical interpretation of $t^{*}$ $<1$ case is that the thermal-wave peak from the opposite solid bed has not yet arrived at the reference solid bed. The limit case is when $t^{*} \rightarrow$ zero, when the thermal-wave propagation speed is approaching zero, or solid bed/HR pipe length is approaching infinity, that the efficiency drop to zero. Beyond the peak efficiency point $t^{*}=1.25$, the efficiency decreases since the additional thermal-wave has the counter effect. The limit case is when $t^{*} \rightarrow$ infinity, or thermodynamic equilibrium state, that the efficiency becomes 0.5 .

Figure 12 shows one of the $t^{*}=0.9$ case when the efficiency is equal to 0.04 . Figure 12 (a) shows the temperature profiles of two solid beds, and Figure 12 (b) plots the snapshots of the temperature distribution within the HR pipe. The steep slope inside the HR pipe is the reason leading to such low HR efficiency, since the outlet temperature remains almost unchanged at least before $t / t_{\mathrm{HR}}=0.5$. The steep slope prevents the high temperature fluid from entering the solid bed, and depresses the key principle to gradually change temperature based on the "time scale counter-flow heat transfer" principle. The remaining almost flat temperature distribution fluid at $t / t_{\mathrm{HR}}=0.99$ further aggravates the opposite steep "thermal-wave" propagation in the next cycle, and therefore causes a continuous low efficient heat recovery performance. When the fluid temperature distributions in Figure 12 (b) and Figure 10 are 
compared, failure to generate the smooth temperature gradient inside HR pipe is the key reason leading to low HR efficiency. It should be noted that the steep thermal-wave in Figure 12 is in fact a desired pattern for the low conductivity application: adsorption cooling.

One observation from Figure 11 is that the HR efficiency is not only dependent on $t^{*}$ when $t^{*}$ is less than 1 , since it diverges at the same $t^{*}$ value. The previous discussion explains the physics for case $t^{*}<1$, that the thermal-wave peak has not yet arrived from the opposite solid-state beds. As a result, the efficiency is sensitive to how far away is the peak, or in other words, the ratio of the solid bed traveling time $l^{*}$. Figure 13 plots the efficiency with various $l^{*}$ when $0.8<t^{*}<1$. One can imagine Figure 13 to be a plane perpendicular to Figure 11 with an additional $3^{\text {rd }}$ coordinate of $l^{*}$. When $t^{*}<1$, the HR efficiency is no longer sensitive to $t^{*}$, but rather dependent on $l^{*}$, vice versa for $t^{*}>1$ cases. Figure 13 also indicates that the minimum efficiency cases discussed in Figure 13 are determined by $l^{*}$, or the geometries of both solid bed and HR pipe. To enhance a high HR performance, a small $l^{*}$ (less than 0.1 ) is recommended based on the trend. It should be noted that for ideal case, there is no temperature gradient in solid and corresponding fluid inside it. However, when $l^{*}>0$ in real case, the conduction loss caused by flow direction temperature gradient degrades the heat recovery performance.

Figure 14 discusses the individual effects of some important design parameters: HR pipe length/diameter and flow velocity. Figure 14 indicates that an optimum HR pipe length exists, since not sufficient temperature gradient is available in a short pipe, and too much pipe wall thermal mass damping effect neutralizes the temperature gradient on the other hand. Figure 14 also indicates that velocity is another key parameter to the HR performance. Lower flow rate results in better HR performance. In ideal cycle from Part $1, \overline{r_{1}}$ is an indirect measure of the heat recovery pipe length, and it predicts better performance with smaller $\bar{r}_{1}$. It is different from the "real" model result, since the counterpart effect from the connecting pipe wall thermal mass is not taken into account for ideal case. On the contrary, the trend that smaller velocity has better efficiency is the same as ideal case, where smaller $\overline{r_{3}}$ tends to have higher efficiency. 
Table 8 summarizes all the degradation factors (or irreversibility) and non-dimensional quantities characterizing them as we discussed above and from Part 1 of this paper. For both ideal case and "real" case, the finite solid thermal mass, finite heat transfer coefficient, and unmatched flow rate are key factors limiting the heat recovery efficiency. When considering real case limitations, if the cycle duration is not controlled appropriately, mixing could happen when a fluid with higher temperature enters the solid that is supposed to be cooled down. This mixing irreversibility is characterized by $t^{*}$. Another equally essential non-dimensional number is $l^{*}$ to measure the irreversibility caused by finite conduction rate inside solid. As pointed out in Part 1, fluid conduction is also a degradation factor, since any diffusion neutralized the preferred stored temperature gradient for the fluid inside the HR pipes. It should be noted that the internal generation/dissipation caused by pump and flow friction are missing from Table 8 for both ideal and real modeling analysis. These two factors can be minimized by higher efficiency pumps and fluid loops with less pressure drop.

\subsection{Design guidelines}

Based on the previous discussion, several guidelines are proposed here for future studies:

- An appropriate HR cycle duration is the key point. The HR duration is slightly higher than the time required for the flow to travel the distance of the solid bed and HR pipe, which is $25 \%$ longer than the traveling time in this study. Quantitatively speaking, $t^{*}=1.25$ is the optimum solution.

- A moderate HR pipe length and diameter is recommended. The HR performance is not sensitive to $l^{*}$ if the cycle duration is chosen wisely, but a too short HR pipe or too long HR pipe could lead to performance degradation, based on Figure 14. Based on results in Figure 13 and Figure 13, $l^{*}$ ranging from $0.05-0.3$ is recommended.

- A small flow velocity leads to a high HR performance. Velocity less than $0.1 \mathrm{~m} / \mathrm{s}$ is recommended based on Figure 14.

- Any asymmetry in heat recovery pipe (length, diameter, material, etc.) should be avoided as much as possible. 
- Appropriate sizing of the pump and valve is necessary. Unnecessary pump heat generation and valve heat generation could lead to imbalance between the cooling efficiency and heating efficiency.

\section{Conclusions}

This study introduces a systematic approach to realize the high efficient heat recovery process for solid-state cooling applications by applying an analogy to the counter-flow heat transfer process. The "time scale counter-flow" heat recovery principle could be approached by fluid with a "smooth" temperature gradient between two solid-state materials. 60\% HR efficiency was experimentally achieved and could be regarded as a successful sign for the method. To understand the limiting factors, an ideal theoretical analysis together with the detailed dynamic modeling were conducted. It was found that two non-dimensional time constants ratios and one time constant were found to be critical parameters affecting the ideal cycle performance, which are the thermal mass ratio between the solid and the fluid inside the heat recovery loop, the heat transfer rate ratio between convective flux rate and conduction heat transfer rate from the wall surface, and the solid transient response time constant. In addition, the dimensionless cycle duration $t^{*}$ and dimensionless length $l^{*}$ are also significant to the performance. Based on the numerical results, a 1.25 dimensionless cycle duration $t^{*}$, a 0.05-0.3 dimensionless length $l^{*}$ and flow velocity less than $0.1 \mathrm{~m} / \mathrm{s}$ are recommended. Degradation factors including irreversibility from the thermal mass of connecting pipes, unmatched heat recovery flow rate, and inappropriate cycle duration should be minimized. The maximum achievable efficiency in this study was 0.6 and 0.88 by experimental and numerical approach, respectively.

\section{Acknowledgements}

The authors gratefully acknowledge the support of this effort from the U.S. DOE and the Center for Environmental Energy Engineering (CEEE) at the University of Maryland. This work was supported by DOE ARPA-E DEAR0000131. 


\section{References}

Anon., 2012. Simulink 8.0 (MATLAB Release 2012b), The MathWorks Inc., Natick, Massachusetts, United States.

Alfeld, G., Radermacher, R., 1994. Heat conversion systems. CRC Press, Florida.

Bonnot, E., Romero, R., Manosa, L., Vives, E., and Planes, A., 2008. Elastocaloric effect associated with the Martensitic transition in shape-memory alloys. Phys. Rev. Lett. 100, 125901. DOI:

10.1103/PhysRevLett.100.125901.

Critoph, R.E., 1994. Forced convective enhancement of adsorption cycles. Heat Recovery Syst. 14, 343350.

Critoph, R.E., 1998. Forced convection adsorption cycles. Appl. Therm. Eng. 18, 799-807.

Cross, C.R., Barclay, J.A., DeGregoria, A.J., Jaeger, S.R., Johnson, J.W., 1988. Optimal temperatureentropy curves for magnetic refrigeration. Adv. Cryog. Eng., 33, 767-775.

Cui, J., Wu, Y., Muehlbauer, J., Hwang, Y., Radermacher R., Fackler, S., et al., 2012. Demonstration of high efficiency elastocaloric cooling with large Delta T using NiTi wires. Appl. Phys. Lett. 101, 073904. DOI: $10.1063 / 1.4746257$.

Gschneidner, K.A., and Pecharsky, V.K., 2000. Magnetocaloric materials. Annu. Rev. Mater.Sci. 30, 387429.

Gu, H., Qian, X., Li, X., Craven, B., Zhu, W., et al., 2013. A chip scale electrocaloric effect based cooling device. Appl. Phys. Lett. 102, 122904. DOI: 10.1063/1.4799283.

Gurgel, J.M., Kluppel, R.P., 1996. Thermal conductivity of hydrated silica-gel. Chem. Eng. J. 61, 133138. Hall, J.L., Reid, C.E., Spearing, I.G., Barclay, J.A., 1996. Thermodynamic considerations for the design of active magnetic regenerative refrigerators. Adv. Cryog. Eng. 41, 1653-1664.

Harkonen, M., and Aittomaki, A., 1991. The principle of internal regeneration as applied to the adsorption heat pump process. Heat Recovery Syst. 11, 239-248. 
Lemmon, E, 2003. Pseudo-Pure Fluid Equations of State for the Refrigerant Blends R-410A, R-404A, R507A, and R-407C. Int. J. Thermophysics. 24(4), 991-1006.

Li, X., Qian, X., Gu, H., Chen, X., Lu, S.G., 2012. Giant electrocaloric effect in ferroelectric poly (vinylidenefluoride-trifluoroethylene) copolymers near a first-order ferroelectric transition. Appl. Phys. Lett. 101, 132903. DOI: 10.1063/1.4756697.

Lu, S.G., and Zhang, Q., 2009. Electrocaloric materials for solid-state refrigeration. Adv. Mater. 21, 1983-1987.

Otsuka, K., Wayman, C.M., 1998. Shape memory materials. Cambridge University Press, Cambridge.

Pons, M., and Poyelle, F., 1999. Adsorptive machines with advanced cycles for heat pumping or cooling applications. Int. J. Refrigeration. 22, 27-37.

Qian, S., Gluesenkamp, K.R., Hwang, Y., Radermacher, R., Chun, H., 2013. Cyclic steady state performance of adsorption chiller with low regeneration temperature zeolite. Energy. 60, 517-526.

Qian, S., Ling, J., Hwang, Y., Radermacher, R. Dynamic performance of a compression thermoelastic cooling air-conditioner under cyclic operation mode. International Refrigeration and Air Conditioning Conference at Purdue. Purdue University, West Lafayette, 2014.

Richard, M.A., Rowe, A.M., Chahine, R., 2004. Magnetic refrigeration: single and multimaterial active magnetic regenerator experiments. J. Appl. Phys. 95, 2146. DOI: 10.1063/1.1643200.

Sharp, J., Bierchenk, J., and Lyon H.B., 2006. Overview of solid-state thermoelectric refrigerators and possible applications to on-chip thermal management. Proceedings of the IEEE, 94, 1602-1612.

Shelton, S.V., Wepfer, W. J., Miles, D. J., 1989. Square wave analysis of the solid-vapor adsorption heat pump. Heat Recovery Syst. 9, 233-237.

Shelton, S.V., Miles, D. J., and Wepfer, W.J., 1990. Ramp wave analysis of the solid-vapor heat pump. J. Energy Resour. Tech. 112(1), 69-78. 
Span, R., and Wagner, R., 1996. A New Equation of State for Carbon Dioxide Covering the Fluid Region from the Triple-Point Temperature to $1100 \mathrm{~K}$ at Pressures up to $800 \mathrm{MPa}$, J. Phys. Chem. Ref. Data. 25(6), 1509-1596.

Sun, L.M., Feng, Y., Pons, M., 1997. Numerical investigation of adsorption heat pump system with thermal wave heat regeneration under uniform-pressure conditions. Int. J. Heat Mass Tran. 40(2), 281-293.

TillnerRoth, R., Harms-Watzenberg, and Baehr, H.D., 1993. Eine neue Fundamentalgleichung fur Ammoniak. DKV-Tagungsbericht. 20, 167-181.

TillnerRoth, R., and Baehr, H.D., 1994. An International Standard Formulation for the Thermodynamic Properties of 1,1,1,2-Tetrafluoroethane (HFC-134a) for Temperatures from $170 \mathrm{~K}$ to $455 \mathrm{~K}$ and Pressures up to 70 MPa. J. Phys. Chem. Ref. Data. 23(5), 657-729.

Yazaki, T., Biwa, T., Tominaga, A., 2002. A pistonless Stirling cooler. Appl. Phys. Lett., 80, 157-159.

Yu, B., Liu, M., Eggolf, P.W., Kitanovski, A., 2010. A review of magnetic refrigerator and heat pump prototypes built before the year 2010. Int. J. Refrigeration. 33, 1029-1060.

Zimm, C., Boeder, A., Chell, J., Sternberg, A., Fujita, A., Fujieda, S., et al., 2006. Design and performance of a permanent-magnet rotary refrigerator. Int. J. Refrigeration. 29, 1302-1306. 


\section{List of Figure Captions:}

Figure 1: Illustration of the role of heat recovery in a cyclic thermoelastic cooling cycle for example.

Figure 2: Illustration of traditional adsorption thermal-wave for low conductivity solid desiccant

application, and novel thermal-wave for high conductivity solid material.

Figure 3: Temperature profiles of the "spatial scale counter-flow heat transfer process" and the time scale counter-flow heat recovery process" for the novel thermal-wave heat recovery process.

Figure 4: Snapshots of fluid temperature distribution along the connecting pipe at different time.

Figure 5: Illustration of the ideal heat recovery cycle model.

Figure 6: An illustration of the schematic of the HR test facility

Figure 7: Temperature profile of two solid walls during the heat-recovery process

Figure 8: The influence of flow rate on the heat recovery efficiency.

Figure 9: Experimental validation of one-dimensional model $\left(t_{\mathrm{HR}}=15 \mathrm{sec}\right)$

Figure 10: Illustration of thermal-wave propagation by snapshot of temperature profiles at different time step during one heat recovery process and corresponding particle trace on the schematic

Figure 11: Parametric study of heat recovery efficiency with non-dimensional cycle time defined in Eq. (14)

Figure 12: An illustration of the low heat recovery efficiency case near $t^{*}=0.9$

Figure 13: Parametric study of heat recovery efficiency with non-dimensional length defined in Eq. (15)

Figure 14: The influence of HR pipe length and velocity on heat recovery efficiency 


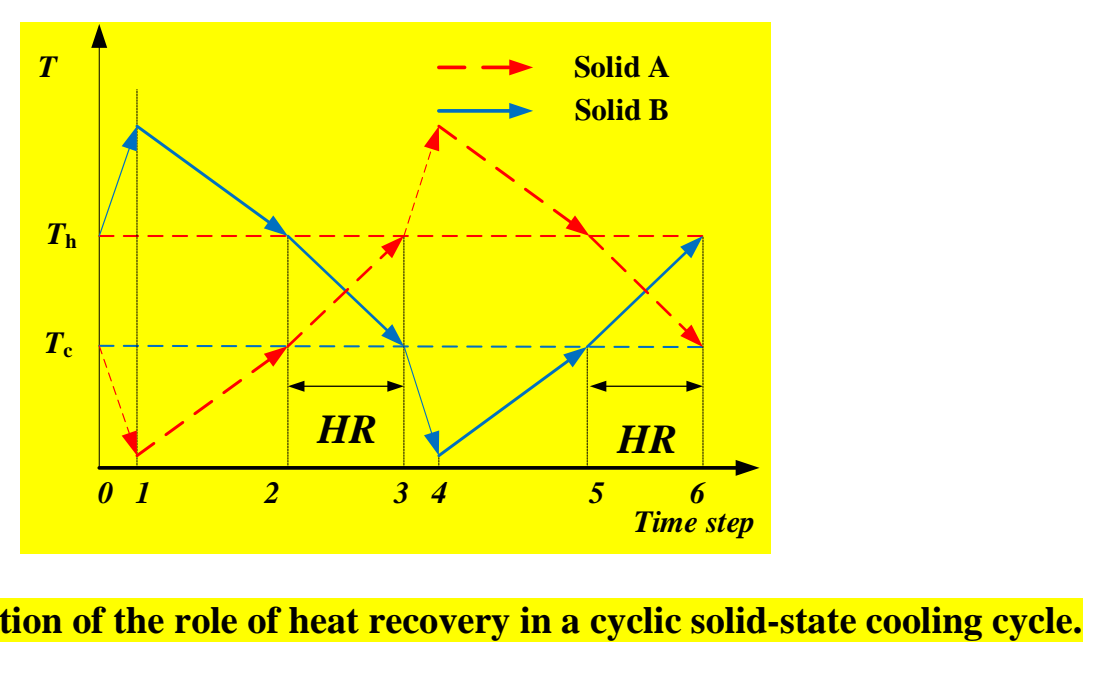

Figure 1: Illustration of the role of heat recovery in a cyclic solid-state cooling cycle.

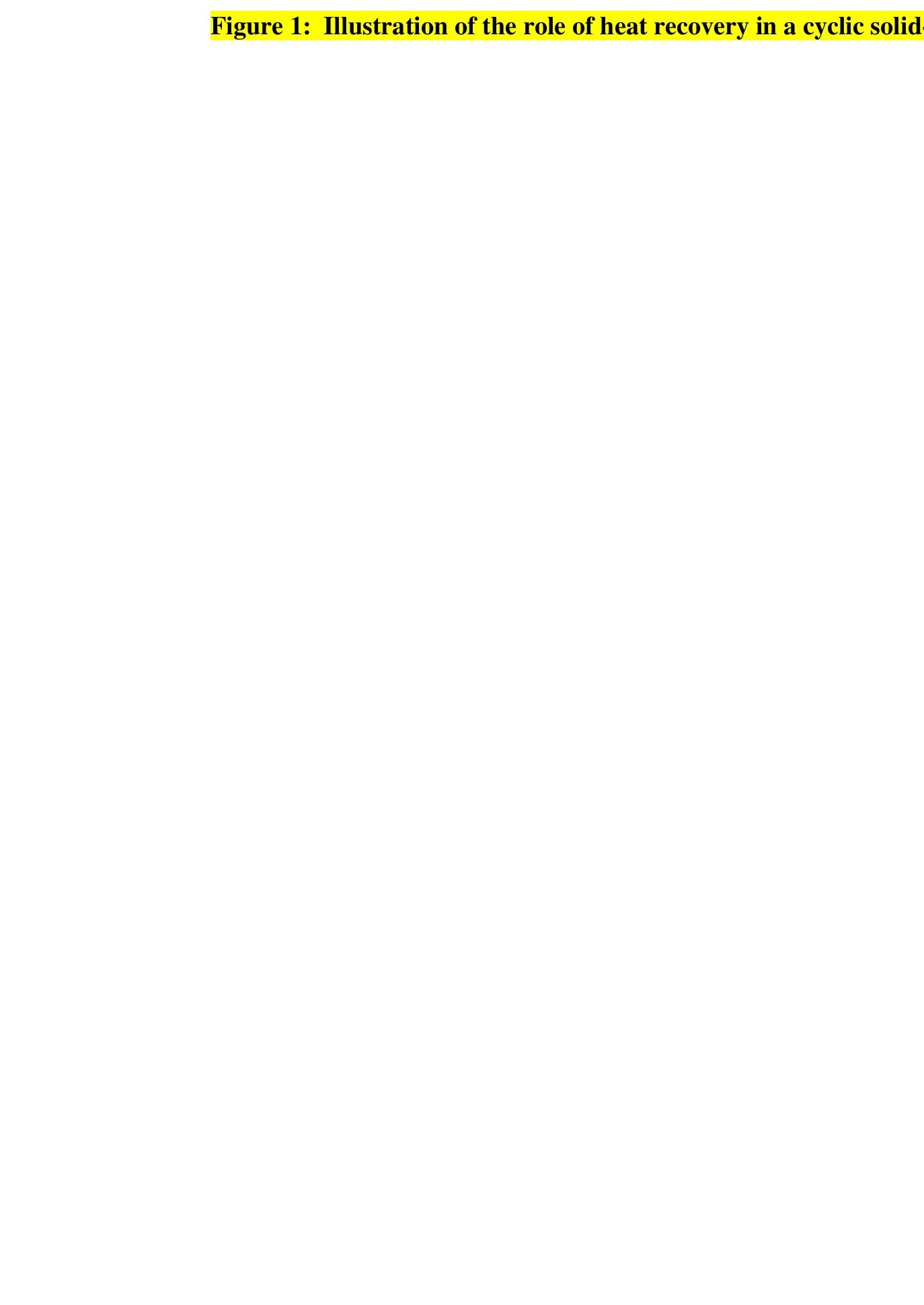



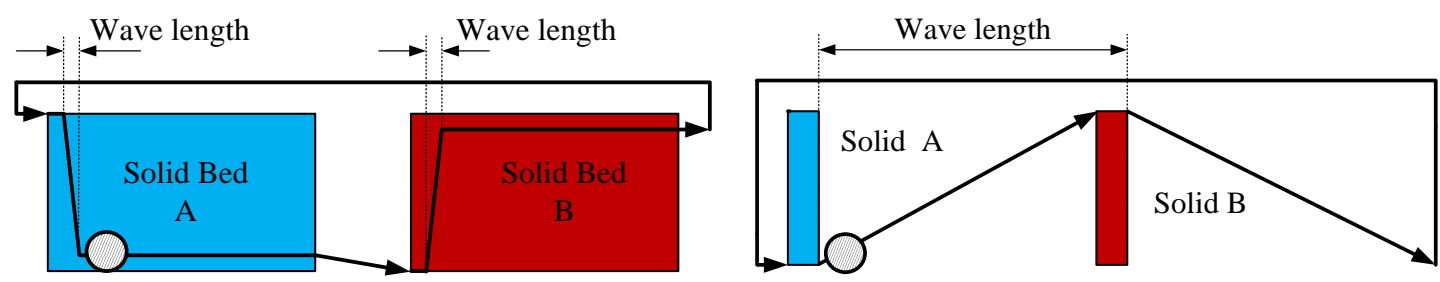

(i) Beginning of the heat recovery

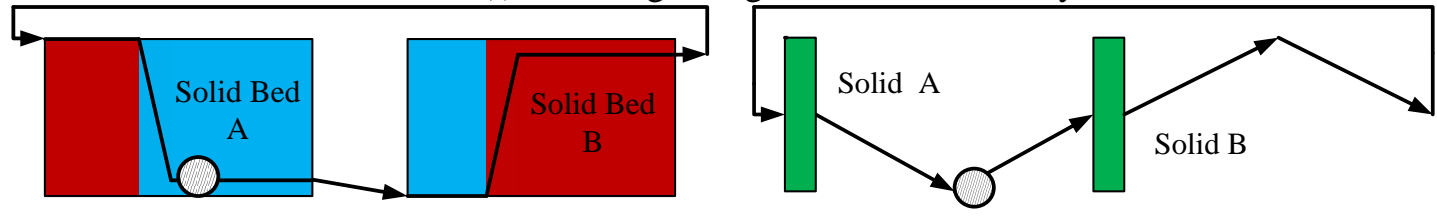

(ii) Heat recovery in progress

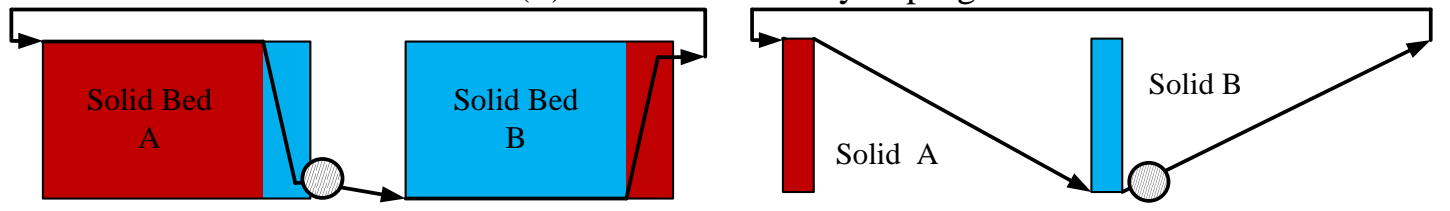

(iii) End of heat recovery

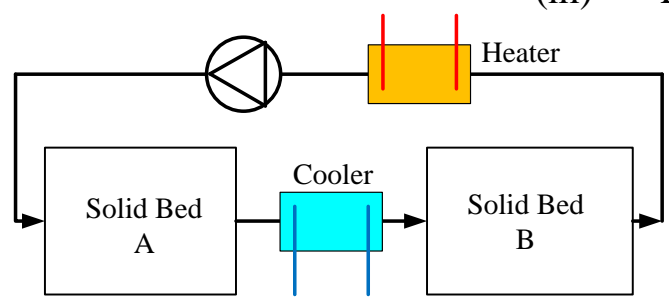

(iv)

(a) Low conductivity solid thermal-wave for adsorption cycles (Shelton et al., 1990)

- Ideal wave length: zero (steep wave)

- Ideal wave pattern: square wave

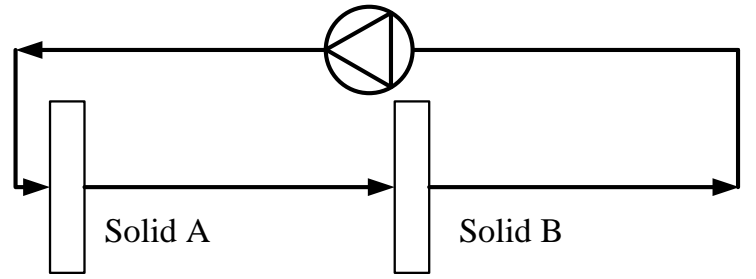

Schematic

(b) High conductivity solid thermal-wave for solidstate cooling cycles (this study)

- Ideal wave length: half loop length (smooth wave)

- Ideal wave pattern: ramp (triangle) wave

Figure 2: Illustration of traditional adsorption thermal-wave for low conductivity solid desiccant application, and novel thermal-wave for high conductivity solid material. 

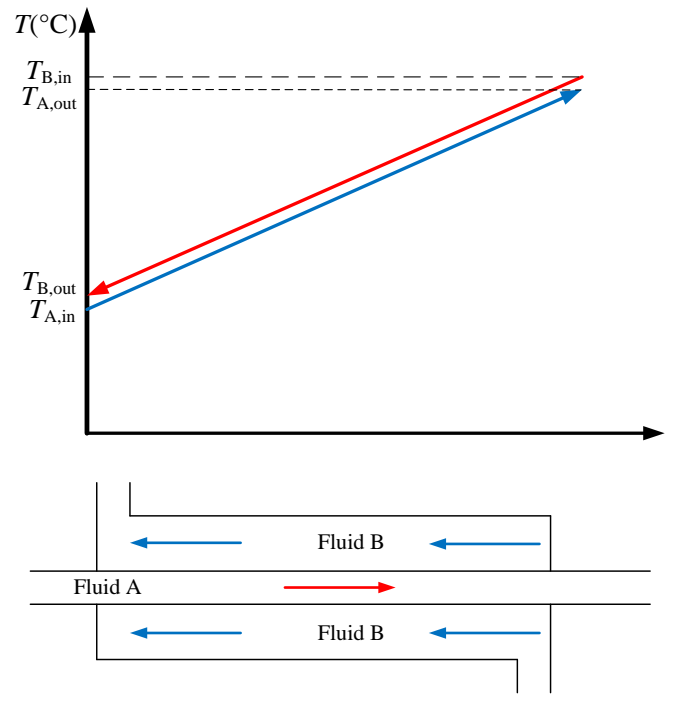

(a) Spatial scale counter-flow heat transfer process

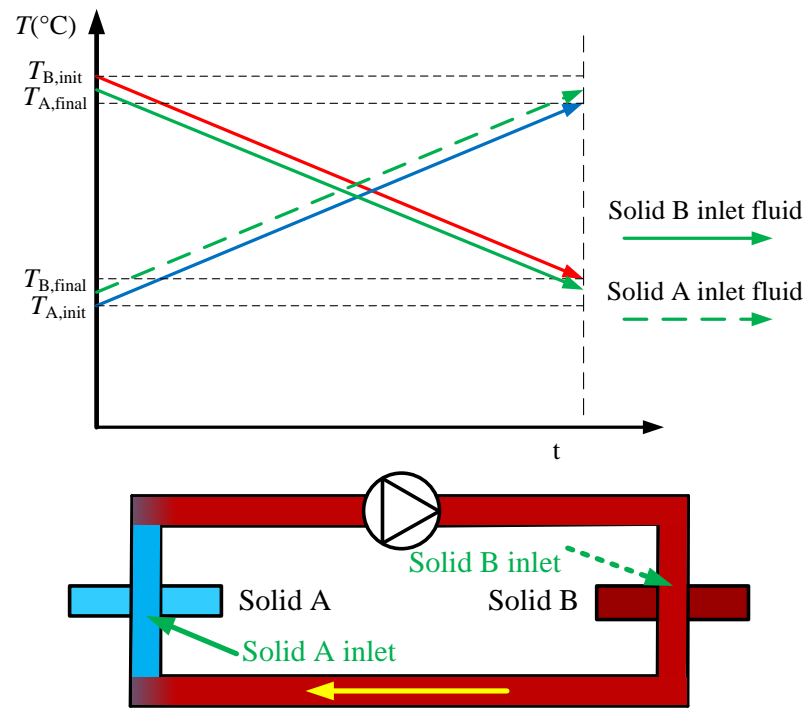

(b) Time scale counter-flow HR process

Figure 3: Temperature profiles of the "spatial scale counter-flow heat transfer process" and the time scale counter-flow heat recovery process" for the novel thermal-wave heat recovery process. 


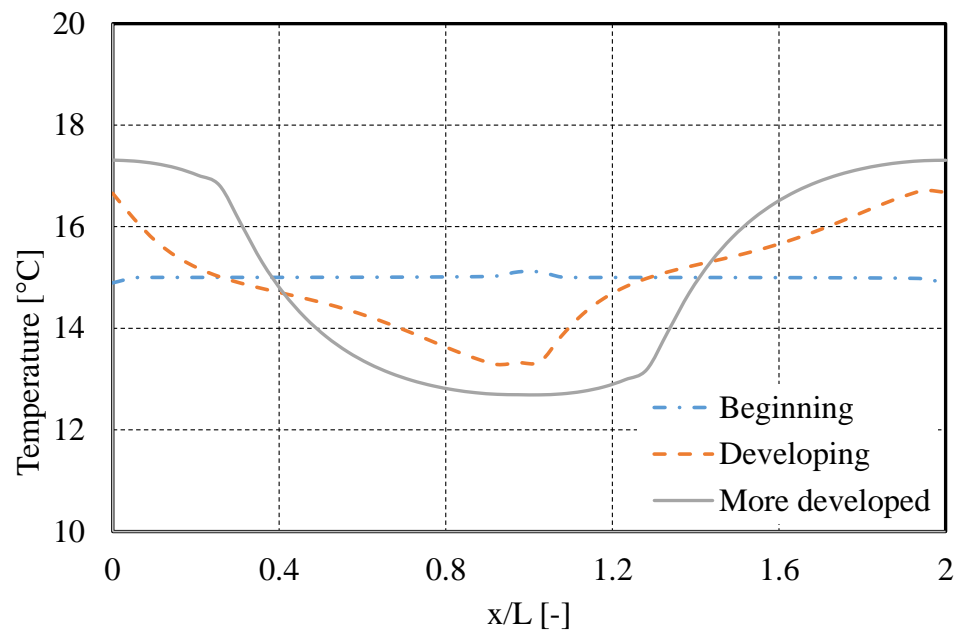

Figure 4: Snapshots of fluid temperature distribution along the connecting pipe at different time. $\left(T_{\mathrm{h}}=20^{\circ} \mathrm{C}, T_{\mathrm{c}}=10^{\circ} \mathrm{C}\right)$ 


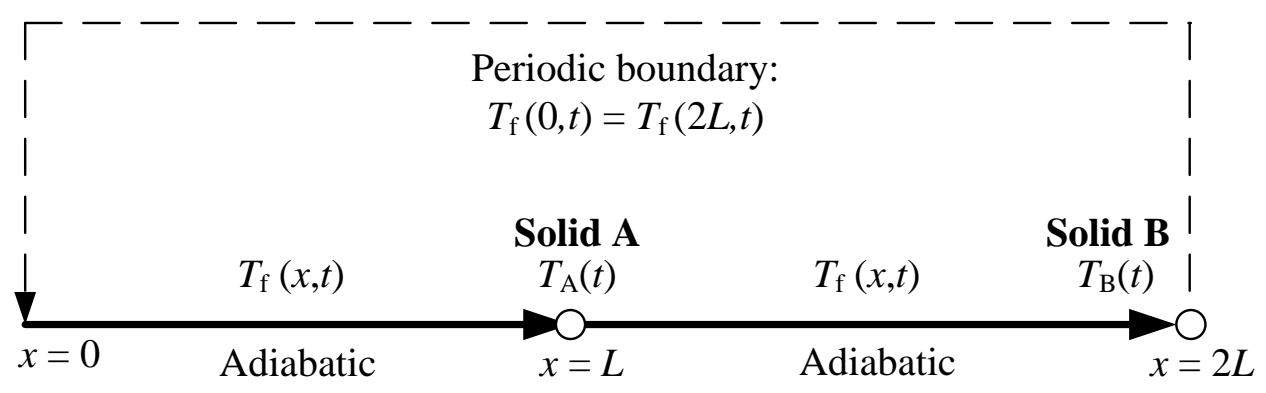

Figure 5: Illustration of the ideal heat recovery cycle model. 


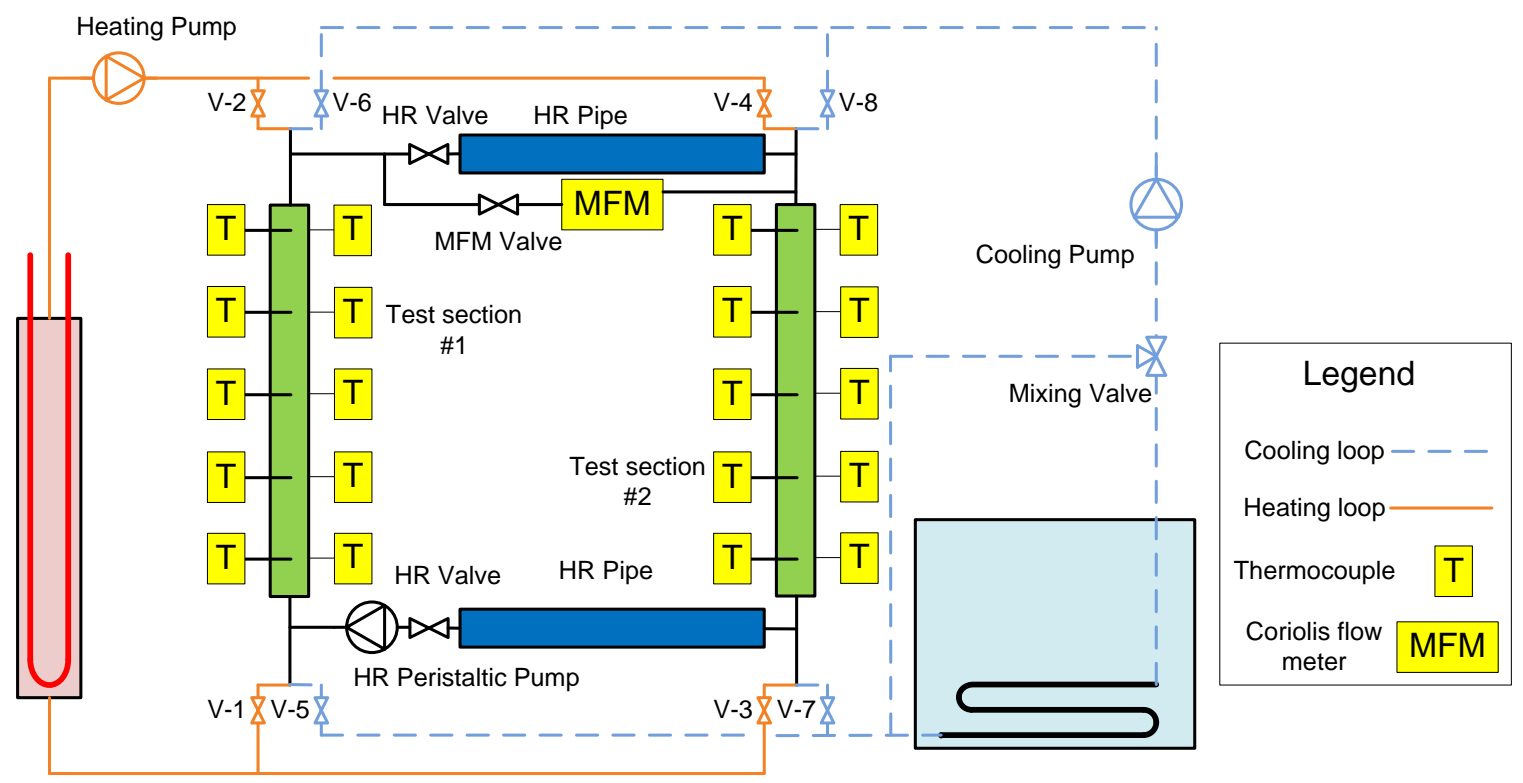

Figure 6: An illustration of the schematic of the HR test facility. 


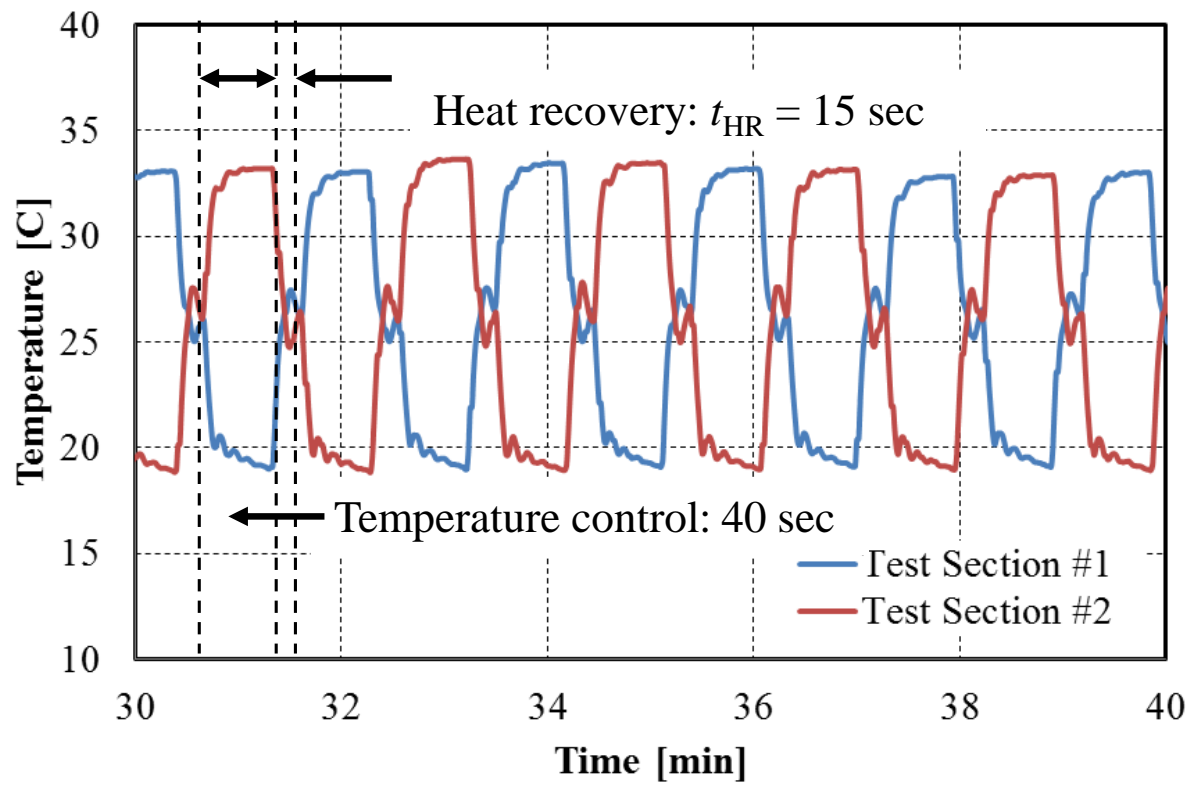

Figure 7: Temperature profile of two solid walls during the heat-recovery process

$$
\left(t_{\mathrm{HR}}=15 \mathrm{sec}, \eta_{\mathrm{h}}=61 \%, \eta_{\mathrm{c}}=59 \%\right) .
$$




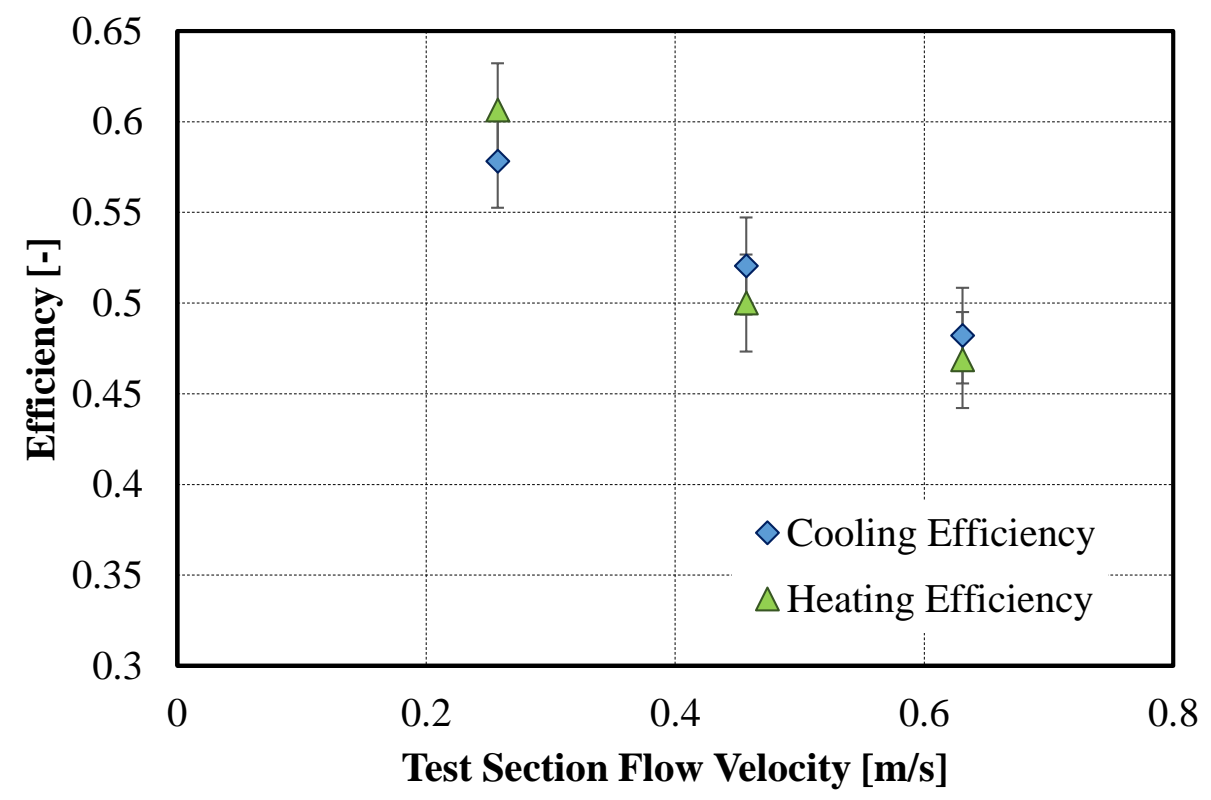

Figure 8: The influence of flow rate on the heat recovery efficiency. 


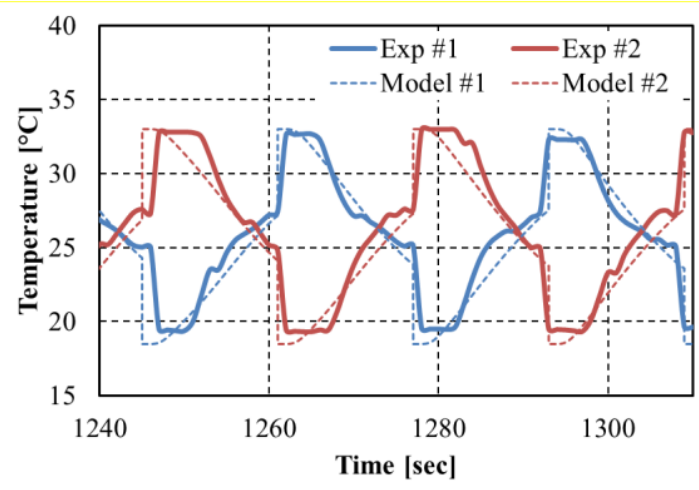

(a) Tested result versus model prediction

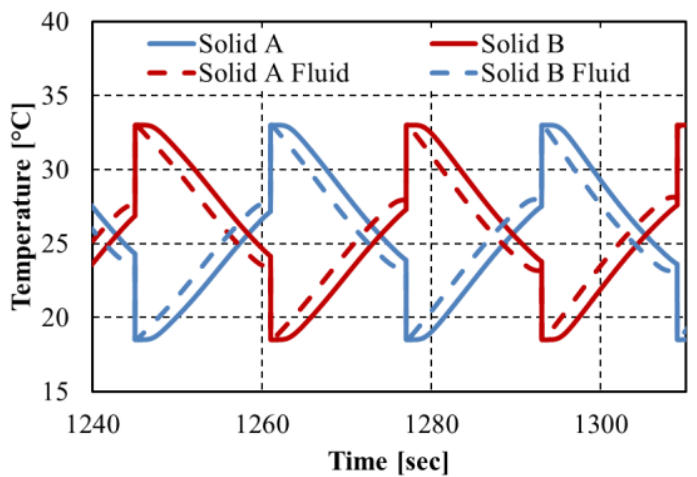

(b) Model predicted fluid and solid temperatures

Figure 9: Experimental validation of one-dimensional model $\left(t_{\mathrm{HR}}=15 \mathrm{sec}\right)$. 

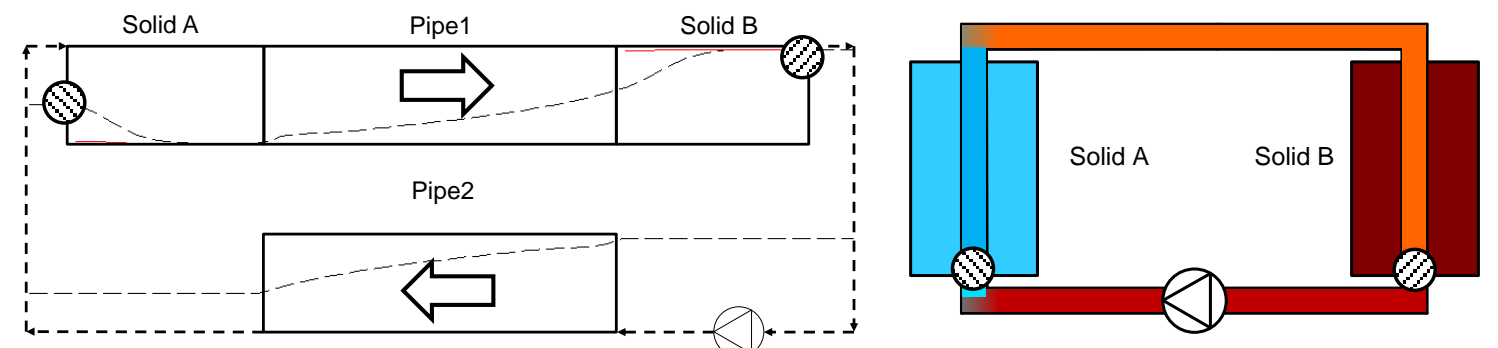

(a) $t / t_{\mathrm{HR}}=0.05$
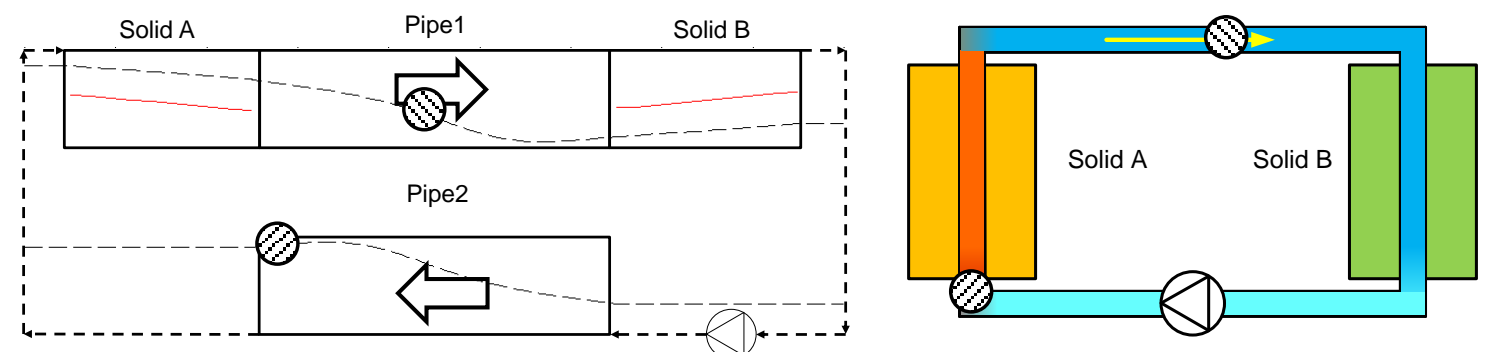

(b) $t / t_{\mathrm{HR}}=0.7$
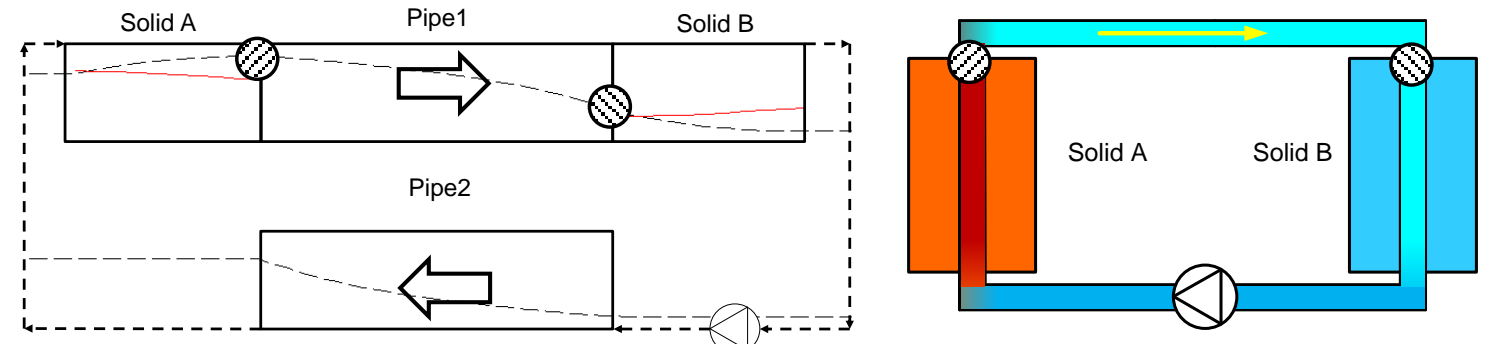

(c) $t / t_{\mathrm{HR}}=0.99$

\section{Legend}

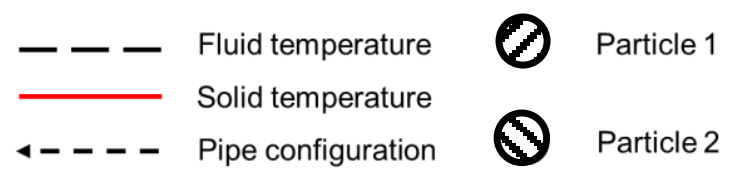

Figure 10: Illustration of thermal-wave propagation by snapshot of temperature profiles at different time step during one heat recovery process and corresponding particle trace on the schematic. 


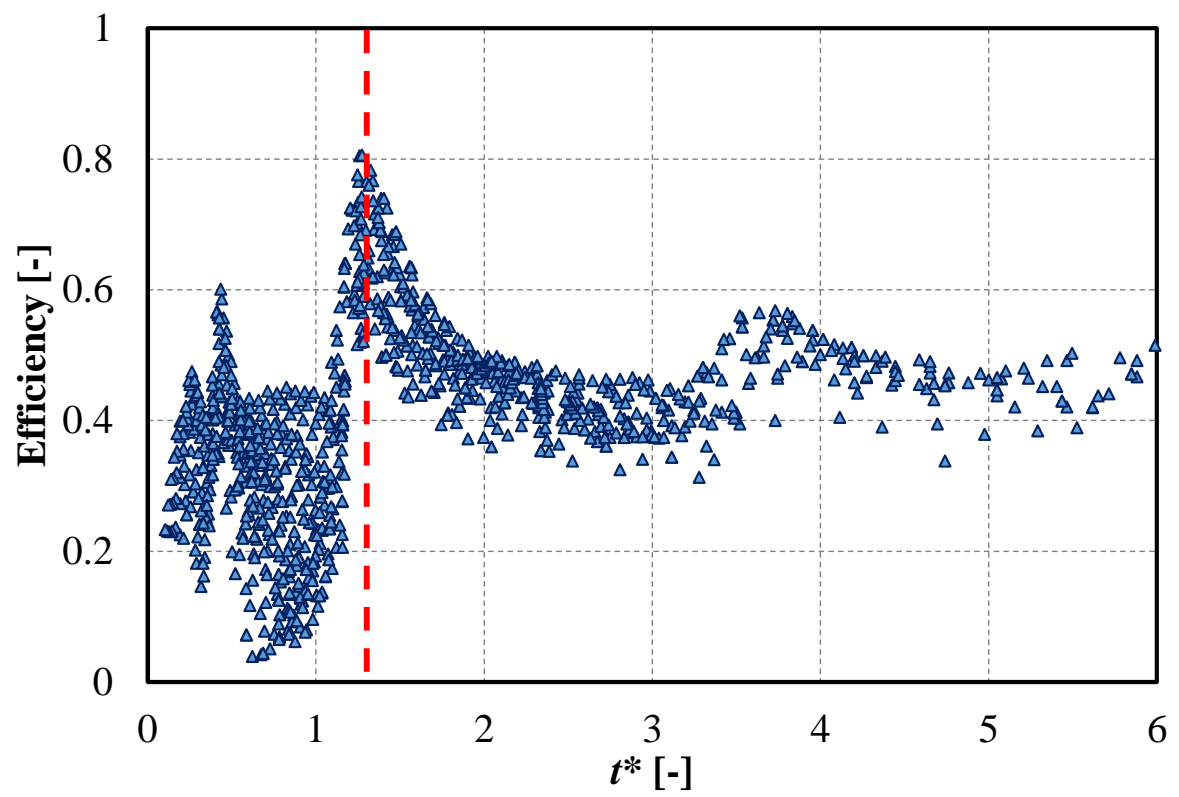

Figure 11: Parametric study of heat recovery efficiency with non-dimensional cycle time defined in Eq. (14).

(Conditions: $0.25 \mathrm{~m}<L<0.75 \mathrm{~m}, 0.1 \mathrm{~m}<L_{\mathrm{HR}}<0.8 \mathrm{~m}, 19 \mathrm{~mm}<I D_{\mathrm{HR}}<38 \mathrm{~mm}, 12 \mathrm{sec}<t_{\mathrm{HR}}$ $<36 \mathrm{sec}, 0.05 \mathrm{~m} / \mathrm{s}<u<0.15 \mathrm{~m} / \mathrm{s}$, corresponding $0.05<l^{*}<0.9$ ) 


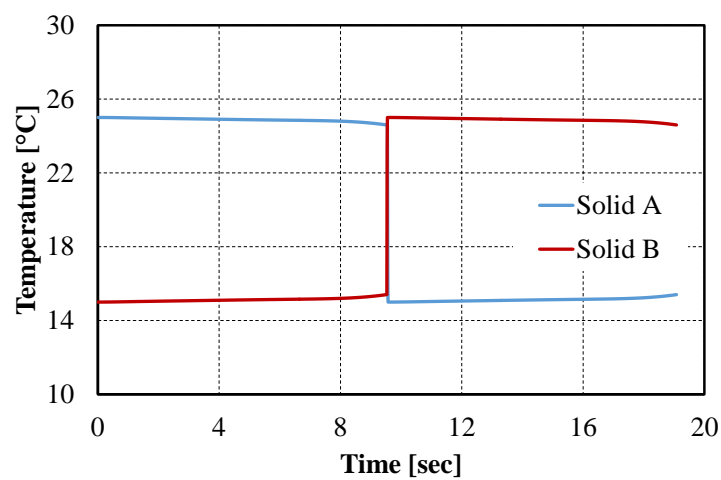

(a) Solid A temperature curves

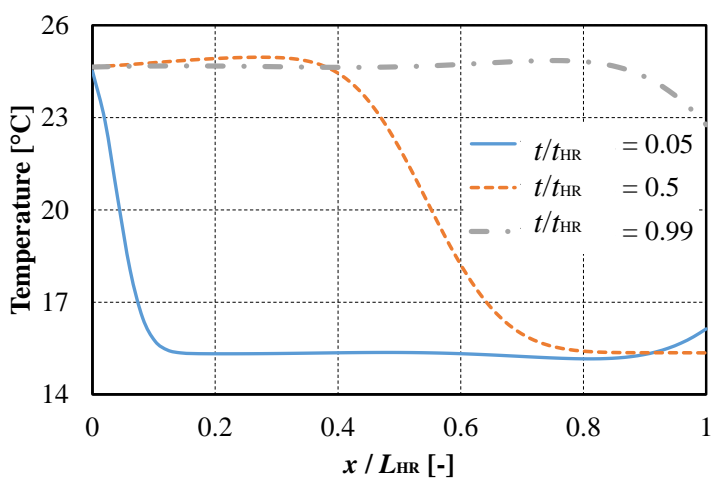

(b) HR pipe temperature distributions

Figure 12: An illustration of the low heat recovery efficiency case near $t^{*}=0.9$.

(Bad case example: $L=0.5 \mathrm{~m}, u=0.1 \mathrm{~m} / \mathrm{s}, L_{\mathrm{HR}}=0.15 \mathrm{~m}, I D_{\mathrm{HR}}=25.4 \mathrm{~mm}, t_{\mathrm{HR}}=9.5 \mathrm{~s}$, or $t^{*}=$ $\left.0.9, l^{*}=0.4\right)$ 


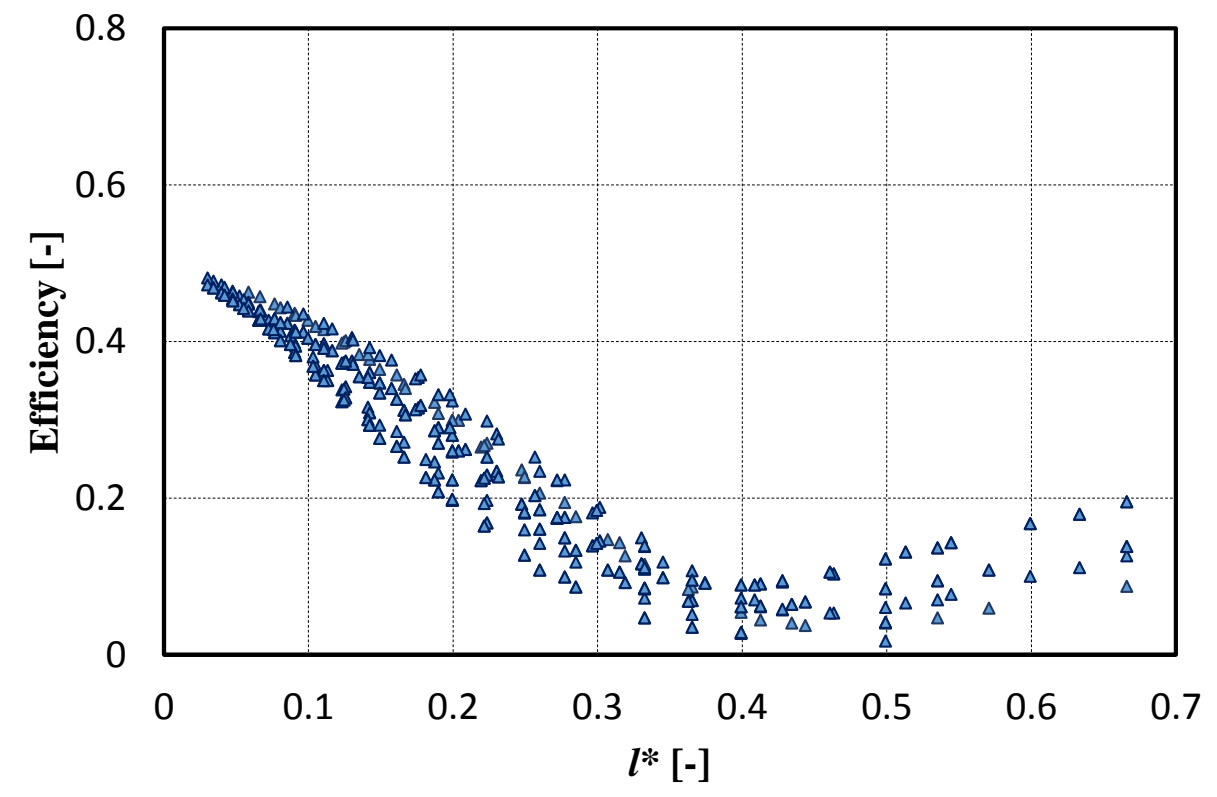

Figure 13: Parametric study of heat recovery efficiency with non-dimensional length defined in Eq. (15).

(Conditions: $0.25 \mathrm{~m}<L<0.75 \mathrm{~m}, 0.1 \mathrm{~m}<L_{\mathrm{HR}}<0.8 \mathrm{~m}, 19 \mathrm{~mm}<I D_{\mathrm{HR}}<38 \mathrm{~mm}, 0.8<t^{*}<1$, $0.1 \mathrm{~m} / \mathrm{s}<u<0.4 \mathrm{~m} / \mathrm{s}$ ) 


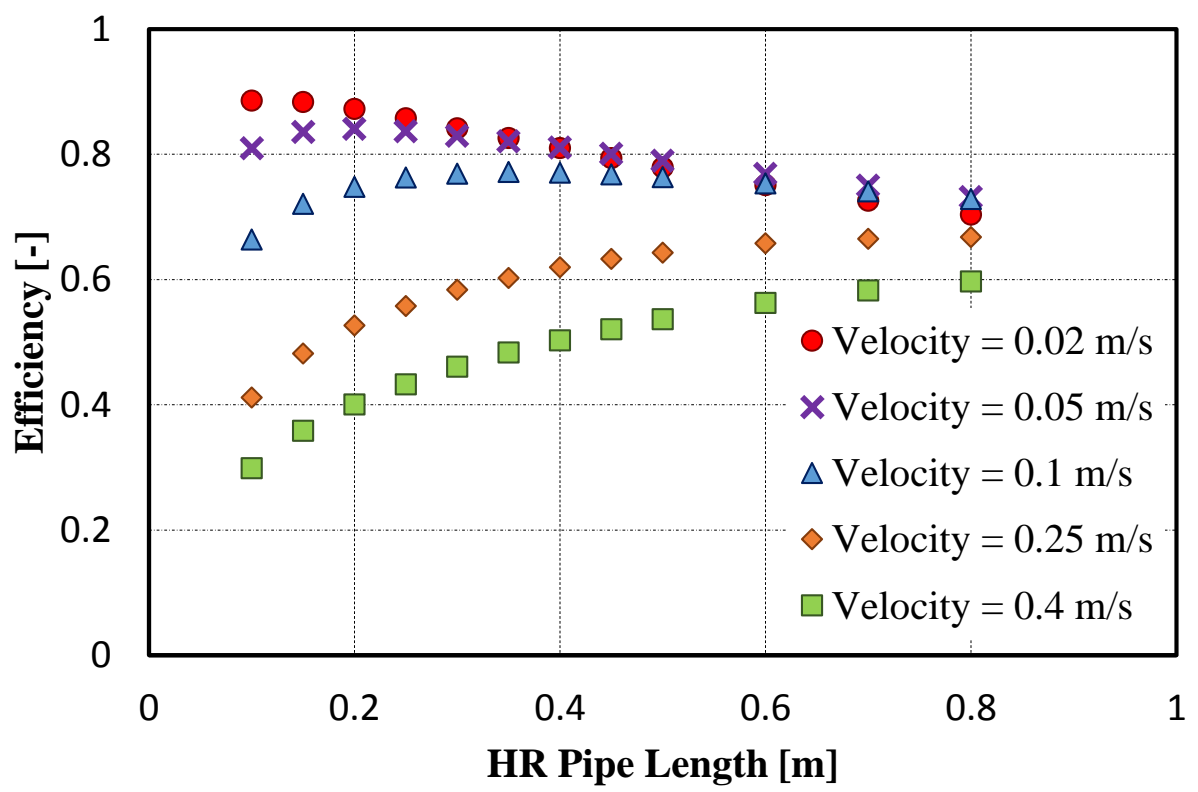

Figure 14: The influence of HR pipe length and velocity on heat recovery efficiency $\left(t^{*}=1.2, I D_{\mathrm{HR}}=39 \mathrm{~mm}\right)$. 
Table 1: Refrigerant ranking using non-dimensional latent heat as index.

\begin{tabular}{|c|c|c|c|c|}
\hline Category & Mechanism & Refrigerant & $\gamma$ & Refrigerant properties source \\
\hline \multirow[t]{4}{*}{ VC cooling } & \multirow[t]{4}{*}{ Vaporization } & R134a & 6.97 & TillnerRoth and Baehr, 1994 \\
\hline & & R410A & 6.62 & Lemmon, 2003 \\
\hline & & $\mathrm{CO}_{2}$ & 3.31 & Span and Wagner, 1996 \\
\hline & & $\mathrm{NH}_{3}$ & 13.1 & TillnerRoth et al., 1993 \\
\hline \multirow[t]{2}{*}{ Magnetocaloric } & \multirow{2}{*}{$\begin{array}{l}\text { Magnetocaloric } \\
\text { effect }\end{array}$} & $\mathrm{Gd}_{5}\left(\mathrm{Si}_{\mathrm{x}} \mathrm{Ge}_{\mathrm{y}}\right)$ & $0.37-0.96$ & \multirow{2}{*}{$\begin{array}{l}\text { Gschneidner and Pecharsky, } \\
2000\end{array}$} \\
\hline & & $\begin{array}{l}\mathrm{GdZn} \\
\mathrm{Tb}_{\mathrm{x}} \mathrm{Y}_{1-\mathrm{x}} \mathrm{Fe}_{2}\end{array}$ & $\begin{array}{l}0.53 \\
0.011-0.065\end{array}$ & \\
\hline \multirow[t]{3}{*}{ Thermoelastic } & \multirow{3}{*}{$\begin{array}{l}\text { Martensite } \\
\text { phase change }\end{array}$} & $\mathrm{NiTi}$ & 1.09 & Cui et al. 2012 \\
\hline & & CuZnAl & 0.68 & \multirow{2}{*}{ Bonnot et al. 2008} \\
\hline & & CuAlNi & 0.70 & \\
\hline \multirow[t]{3}{*}{ Electrocaloric } & \multirow{3}{*}{$\begin{array}{l}\text { Ferroelectric } \\
\text { polarization } \\
\text { change }\end{array}$} & $\mathrm{BaTiO}_{3}$ & 0.14 & \multirow{2}{*}{ Lu and Zhang, 2009} \\
\hline & & $\begin{array}{l}\mathrm{Pb}\left(\mathrm{Zr}_{\mathrm{x}} \mathrm{Ti}_{1-\mathrm{x}}\right) \mathrm{O}_{3} \\
\mathrm{P}(\mathrm{VDF}-\mathrm{TrFF}) * *\end{array}$ & $\begin{array}{l}0.13 \\
011-036\end{array}$ & \\
\hline & & P(VDT-115E) & $0.11-0.50$ & 2012 \\
\hline
\end{tabular}


Table 2: Summary of analogy of spatial scale counter-flow heat transfer process to time scale counter-flow heat recovery process.

\begin{tabular}{lllll}
\hline $\begin{array}{l}\text { Spatial scale counter-flow heat } \\
\text { process }\end{array}$ & transfer & Time scale counter-flow HR process \\
\hline Inlet temperature & $T_{i n}[\mathrm{~K}]$ & Initial temperature & $T_{\text {init }}[\mathrm{K}]$ \\
Heat exchanger capacity & $\dot{Q}[\mathrm{~W}]$ & Heat transferred & $Q[\mathrm{~J}]$ \\
Temperature slope & $\nabla T[\mathrm{~K} / \mathrm{m}]$ & Temperature slope & $\dot{T}[\mathrm{~K} / \mathrm{s}]$ \\
Effectiveness & $\varepsilon[-]$ & Heat recovery efficiency & $\eta[-]$ \\
Max. effectiveness & $100 \%$ & Max. efficiency & $100 \%$ \\
Thermal resistance & $R[\mathrm{~K} / \mathrm{W}]$ & & Transient resistance & $R[\mathrm{~K} / \mathrm{J}]$ \\
$\dot{Q}=\dot{m}_{f} c_{p, f}\left(T_{f, \text { out }}-T_{f, \text { in }}\right)=\frac{L M T D}{R}$ & & $Q=m_{s} c_{p, s}\left(T_{s, \text { final }}-T_{s, \text { init }}\right)=\frac{T_{s 2 \text {,init }}-T_{s 1 \text {,init }}}{R}$ \\
\hline
\end{tabular}


Table 3: Non-dimensional ratios and time constants characterizing the ideal HR cycle.

\begin{tabular}{|c|c|c|c|}
\hline Quantities & Definition & Physical interpretation & Contribution \\
\hline$\overline{r_{1}}[-]$ & $\bar{r}_{1}=\frac{\left(m c_{p}\right)_{s}}{\left(m c_{p}\right)_{f, H R}}$ & $\begin{array}{l}\text { - Thermal mass ratio between the solid and the } \\
\text { fluid inside the connecting heat recovery pipe. } \\
\text { - A non-dimensional measure of solid thermal } \\
\text { mass. }\end{array}$ & $\begin{array}{l}\text { Smaller } \overline{r_{1}} \text {, } \\
\text { better } \\
\text { efficiency }\end{array}$ \\
\hline$\overline{r_{2}}[-]$ & $\bar{r}_{2}=\frac{\left(m c_{p}\right)_{f, s}}{\left(m c_{p}\right)_{s}}$ & $\begin{array}{l}\text { - Thermal mass ratio between the fluid inside } \\
\text { the solid heat exchanger and solid. } \\
\text { - A non-dimensional measure of solid/fluid } \\
\text { thermal mass ratio inside solid heat exchanger }\end{array}$ & $\begin{array}{l}\text { Not } \\
\text { significant }\end{array}$ \\
\hline$\overline{r_{3}}[-]$ & $\frac{\left(\dot{m} c_{p}\right)_{f}}{h A}$ & $\begin{array}{l}\text { - Heat transfer rate ratio between convective } \\
\text { flux rate through flow and conduction from the } \\
\text { solid wall surface. } \\
\text { - A non-dimensional measure of flow rate or } h \text {. }\end{array}$ & $\begin{array}{l}\text { Smaller } \overline{r_{3}} \text {, } \\
\text { better } \\
\text { efficiency }\end{array}$ \\
\hline$t_{1}[\mathrm{sec}]$ & $t_{1}=\frac{L}{u}=\frac{\left(m c_{p}\right)_{f, H R}}{\left(\dot{m} c_{p}\right)_{f}}$ & $\begin{array}{l}\text { - Ratio between fluid thermal mass inside } \\
\text { connecting pipe and heat capacity rate. } \\
\text { - It measures the time for fluid to travel between } \\
\text { two solids. }\end{array}$ & $\begin{array}{l}\text { Not } \\
\text { independent } \\
\text { variable }\end{array}$ \\
\hline$t_{2}[\mathrm{sec}]$ & $\frac{\left(m c_{p}\right)_{s}}{h A}$ & $\begin{array}{l}\text { - Ratio between the thermal mass of solid and } \\
\text { heat transfer coefficient. } \\
\text { - It measures the transient response speed of } \\
\text { solid. }\end{array}$ & $\begin{array}{l}\text { Smaller } t_{2} \text {, } \\
\text { better } \\
\text { efficiency }\end{array}$ \\
\hline$t_{3}[\mathrm{sec}]$ & $\frac{\left(m c_{p}\right)_{f, s}}{A+\left(\dot{m} c_{n}\right)}$ & $\begin{array}{l}\text { - Ratio between the thermal mass of fluid inside } \\
\text { solid heat exchanger and a sum of heat transfer } \\
\text { coefficient and flow heat capacity rate. } \\
\text { - It measures the transient response speed of } \\
\text { fluid inside the solid when it interacts with } \\
\text { flowing fluid and solid at the same time. }\end{array}$ & $\begin{array}{l}\text { Not } \\
\text { independent } \\
\text { variable }\end{array}$ \\
\hline
\end{tabular}


Table 4: Some important parameters of the test facility.

\begin{tabular}{|c|c|c|c|}
\hline & Test section & HR pipe & Cooling and heating loop \\
\hline Material & Stainless steel SS316 & PVC, clear PVC & Clear PVC \\
\hline$I D[\mathrm{~mm}]$ & 11.8 & $\begin{array}{l}25.4 / 12.7 \text { for } \mathrm{PVC} / \mathrm{clear} \\
\mathrm{PVC}\end{array}$ & 12.7 \\
\hline$O D[\mathrm{~mm}]$ & 12.7 & $\begin{array}{l}28.6 / 15.9 \text { for } \mathrm{PVC} / \mathrm{clear} \\
\mathrm{PVC}\end{array}$ & 15.9 \\
\hline Length $[\mathrm{m}]$ & 0.5 & $\begin{array}{ll}0.3 / 0.7 & \text { for } \mathrm{PVC} / \mathrm{clear} \\
\mathrm{PVC} & \end{array}$ & I \\
\hline Valves & I & $2 \mathrm{x}$ electric actuated valves & $8 \mathrm{x}$ solenoid valves \\
\hline$\kappa[-] *$ & / & $\begin{array}{l}\text { 1.09/1.24 for } \mathrm{PVC} / \text { clear } \\
\mathrm{PVC}\end{array}$ & 1.24 \\
\hline
\end{tabular}

Note: $\kappa$ is defined in Eq. (13) for connecting pipes between two test sections. 
Table 5: Valve and pump sequences for the HR test.

\begin{tabular}{|c|c|c|c|c|}
\hline \multirow[t]{2}{*}{ Actuators } & \multicolumn{2}{|c|}{$1^{\text {st }}$ half cycle } & \multicolumn{2}{|c|}{$2^{\text {nd }}$ half cycle } \\
\hline & $\begin{array}{c}\text { Temperature } \\
\text { control }\end{array}$ & HR & $\begin{array}{c}\text { Temperature } \\
\text { control }\end{array}$ & HR \\
\hline $\mathrm{V} 1, \mathrm{~V} 2, \mathrm{~V} 7, \mathrm{~V} 8$ & $\mathrm{O}$ & $\bar{X}$ & $\mathrm{X}$ & $\bar{X}$ \\
\hline $\mathrm{V} 3, \mathrm{~V} 4, \mathrm{~V} 5, \mathrm{~V} 6$ & $\mathrm{X}$ & $\mathrm{X}$ & $\mathrm{O}$ & $\mathrm{X}$ \\
\hline MFM Valve & $\mathrm{X}$ & $\mathrm{X}$ & $\mathrm{X}$ & $\mathrm{X}$ \\
\hline HR valves & $\mathrm{X}$ & $\mathrm{O}$ & $\mathrm{X}$ & $\mathrm{O}$ \\
\hline Cooling + Heating Pumps & $\mathrm{O}$ & $\mathrm{X}$ & $\mathrm{O}$ & $\mathrm{X}$ \\
\hline HR pump & $\mathrm{X}$ & $\mathrm{O}$ & $\mathrm{X}$ & $\mathrm{O}$ \\
\hline
\end{tabular}

Note: O represents open; $\mathrm{X}$ represents closed. 
Table 6: Comparison between ideal HR model and 1-D real case model.

\begin{tabular}{llll}
\hline Objects & Features & Ideal HR model & Real case model \\
\hline \multirow{2}{*}{ Solid } & Solid length & Infinitesimal & Finite \\
Fluid inside solid & Solid conduction & No & Yes, 1-D \\
heat exchanger & Fluid length & Infinitesimal & Finite \\
& Fluid conduction & No & Yes, 1-D \\
Fluid in HR & Pipe wall effect & No & Yes, lumped \\
connecting pipe & Heat loss to ambient & No & Yes \\
& through pipe wall & No & Yes, 1-D \\
\hline
\end{tabular}


Table 7: Experimental validation of one-dimensional model.

\begin{tabular}{cccccccc}
\hline & $t_{\mathrm{HR}}[\mathrm{s}]$ & $u[\mathrm{~m} / \mathrm{s}]$ & $\eta_{\text {experimental }}[-]$ & $\eta_{\text {numerical }}[-]$ & Deviation [\%] & $t^{*}[-]$ & $l^{*}[-]$ \\
\hline 1 & 15 & 0.25 & 0.61 & 0.64 & $5 \%$ & 1.34 & 0.18 \\
2 & 13 & 0.46 & 0.5 & 0.52 & $4 \%$ & 1.53 & 0.18 \\
3 & 11 & 0.63 & 0.47 & 0.45 & $-4 \%$ & 1.57 & 0.18 \\
\hline \multicolumn{7}{l}{ Note: $t^{*}$ and $l^{*}$ are defined in Eqs. (14) and (15), respectively. }
\end{tabular}

Note: $t^{*}$ and $l^{*}$ are defined in Eqs. (14) and (15), respectively. 
Table 8: A summary of degradation factors (irreversibility) during the heat recovery process.

\begin{tabular}{llllllll}
\hline & $\begin{array}{l}\text { Solid length } \\
\text { (axial } \\
\text { conduction) }\end{array}$ & $\begin{array}{l}\text { Solid } \\
\text { thermal } \\
\text { mass }\end{array}$ & $\begin{array}{l}\text { Connecting } \\
\text { pipe thermal } \\
\text { mass }\end{array}$ & $\begin{array}{l}\text { Heat } \\
\text { transfer } \\
\text { coefficient }\end{array}$ & $\begin{array}{l}\text { Fluid } \\
\text { conduction }\end{array}$ & $\begin{array}{l}\text { Mixing caused } \\
\text { by inappropriate } \\
t_{\mathrm{HR}}\end{array}$ & $\begin{array}{l}\text { Unmatched } \\
\text { flow rate }\end{array}$ \\
\hline Ideal & - & $\overline{r_{1}}$ & - & $t_{2}$ & - & - & $\overline{r_{3}}$ \\
Real & $l^{*}$ & $\overline{r_{1}}$ & $\kappa($ Eq. 13) & $t_{2}$ & Fo $\left(t_{1}\right)$ & $t^{*}$ & $\overline{r_{3}}$ \\
\hline
\end{tabular}

